IZA DP No. 6774

How General Are Time Preferences?

Eliciting Good-Specific Discount Rates

Diego Ubfal

July 2012 


\title{
How General Are Time Preferences? Eliciting Good-Specific Discount Rates
}

\author{
Diego Ubfal \\ University of California at Los Angeles \\ and IZA
}
Discussion Paper No. 6774
July 2012

IZA
P.O. Box 7240
53072 Bonn
Germany

Phone: +49-228-3894-0

Fax: +49-228-3894-180

E-mail: iza@iza.org

\begin{abstract}
Any opinions expressed here are those of the author(s) and not those of IZA. Research published in this series may include views on policy, but the institute itself takes no institutional policy positions.

The Institute for the Study of Labor (IZA) in Bonn is a local and virtual international research center and a place of communication between science, politics and business. IZA is an independent nonprofit organization supported by Deutsche Post Foundation. The center is associated with the University of Bonn and offers a stimulating research environment through its international network, workshops and conferences, data service, project support, research visits and doctoral program. IZA engages in (i) original and internationally competitive research in all fields of labor economics, (ii) development of policy concepts, and (iii) dissemination of research results and concepts to the interested public.
\end{abstract}

IZA Discussion Papers often represent preliminary work and are circulated to encourage discussion. Citation of such a paper should account for its provisional character. A revised version may be available directly from the author. 


\section{ABSTRACT \\ How General Are Time Preferences? Eliciting Good-Specific Discount Rates ${ }^{*}$}

This paper tests the broadly adopted assumption that people apply a single discount rate to the utility from different sources of consumption. Using unique data from two surveys conducted in rural Uganda including both hypothetical and real choices over different goods, the paper elicits time preferences from approximately 2,400 subjects. The data reject the null of equal discount rates across goods under a number of different modeling assumptions. These results have important theoretical and policy implications. For instance, they provide support for the idea that time-inconsistent behaviors and a corresponding demand for commitment can be observed even if individuals do not exhibit horizon-specific discounting. In addition, good-specific discounting, under certain conditions, can explain the persistence of poverty and low savings by the poor. The paper presents evidence that these conditions are satisfied in the context under study by showing that the share of expenditures on those goods with higher discount rates is decreasing with income.

JEL Classification: D01, D91, O1

Keywords: time preferences, self-control problems, good-specific discounting, savings, poverty traps

Corresponding author:

Diego Ubfal

Department of Economics

University of California at Los Angeles

P.O. Box 951477

Los Angeles, CA 90095

USA

E-mail: dubfal@ucla.edu

\footnotetext{
* I thank Pascaline Dupas and Adriana Lleras-Muney for their invaluable comments and constant feedback. I am also grateful to Jon Robinson, Rob Jensen, Max Kasy, Leandro Gorno and Aaron Dibner-Dunlap. Special thanks to the participants of UCLA Albert Family Fund Seminar in Applied Microeconomics, and seminar participants at Bocconi, CEMFI, Geneve, Georgetown Qatar, IFPRI, IZA, Pompeu Fabra, IDB RES and Warwick for many useful comments. I also want to thank Natalie Greene and Catlan Reardon for their excellent field management, and the IPA Uganda enumerators for their assistance with the data collection. All errors are my own.
} 


\section{Introduction}

People are in many circumstances unable to be consistent with their own plans. A number of papers in economics explain self-control problems as the consequence of time-inconsistent preferences. Most empirical research has focused on providing evidence for discount rates not being constant, but decreasing over the time horizon 11 This idea of horizon-specific discount rates is captured in the models by Laibson (1997) and O'Donoghue and Rabin (1999) building on Strotz (1956) and Phelps and Pollak (1968). Nevertheless, this is only one possible deviation from the broadly adopted discounted utility framework introduced by Samuelson (1937). An alternative way to model time-inconsistent behaviors is by assuming good-specific discount rates. The possibility that different discount rates are applied to the utility from different sources of consumption has been recently introduced in the models by Banerjee and Mullainathan (2010) and Futagami and Hori (2010), but there is scarce evidence that evaluates its empirical validity.

This paper attempts to fill this gap in the empirical literature by testing for differences in discount rates across a large list of goods. We adapt the procedures and the econometric techniques used to elicit discount rates for monetary rewards in order to estimate discount rates over real consumption goods. There are only a few papers in the economic literature eliciting time preferences over consumption goods and they do not focus on testing for differences in discount rates (see section 2.1 below). While there are a series of studies in the literature from psychology finding "domain-effects" or different discount rates across domains, they are mainly qualitative. Moreover, their results are typically derived from small samples of students answering hypothetical questions in the lab. Our study is the first to estimate discount rates for several goods using both hypothetical and real choices. Results are based on time-preference choices made in the field by more than 2,400 individuals in a rural area of Central Uganda.

The challenge to elicit time preferences is significant since a myriad of contextual factors that can affect the results have to be taken into account.2 We show that differences in discount rates persist after controlling for several potential confounders that have not been taken into account in the previous literature. For example, we consider the curvature of the utility function, the possibility that rewards are not immediately consumed, and reward magnitude effects. In addition, we control for individual characteristics by using withinindividual variation in discounting choices across goods, as well as for good-specific potential

\footnotetext{
${ }^{1}$ See, for example, the literature surveyed in DellaVigna (2009) and Bryan et al. (2010) including both hyperbolic and quasi-hyperbolic models.

${ }^{2}$ See Frederick et al. (2002) and Chabris et al. (2008) for a list of potential confounding factors when eliciting monetary discount rates.
} 
confounders (expected prices, storage capabilities, uncertainty about receiving future payments and trade opportunities). Furthermore, we find that discount rates for each good are strongly correlated with two self-reported variables measuring time-preferences: the desire to have the good at the present, and the desire to have the good in the future. This provides evidence that the estimated discount rates are indeed capturing individual time preferences and not other confounding factors.

The data reject equality of discount rates across goods under several modeling assumptions. For the sample of rural households in Central Uganda, there are three goods with significantly higher discount rates than money: sugar, beef and matooke (a green plantain, main staple in the region). Almost half of the sample exhibit higher discount rates for at least one of these three goods than for money. We find that there is evidence for context specificity in the sense that discount rates differ across goods, but also some support for general components of time preferences since similar observable factors affect time choices for different goods and there is a high correlation in discount rates across goods. These results are similar to those found by Einav et al. (2010) for risk preferences.

The finding that the discount rate varies across goods has three important implications. First, it implies that time-inconsistent behaviors can be observed even if individuals do not exhibit horizon-specific discounting. Second, it has implications for optimal taxation. For example, Futagami and Hori (2010) show that if agents discount the utility from consumption and leisure differently, the optimal consumption tax in general equilibrium will not be zero (zero being optimal under both time-consistent and horizon-specific discounting).

Third, good-specific discounting, under certain conditions, can explain the persistence of poverty and low savings by the poor. Banerjee and Mullainathan (2010) develop a model to show that when different discount rates across goods are combined with the assumption that expenditures in those goods with higher discount rates increase less than proportionally with income $!^{3}$ a poverty trap can emerge $!^{4}$ The intuition for their model is that under these assumptions, there will be a disagreement between the present and the future self on the composition of consumption for both the rich and the poor. If the poor are aware that their future self will spend a relatively large share of their income on the high-discount goods (the "temptation tax" in words of Banerjee and Mullainathan), their present self will try to limit the resources available for the future self by increasing present consumption. Wealthier individuals spend a low share on these goods, and their disincentive to save will be negligible.

\footnotetext{
${ }^{3}$ In related work, Moav and Neeman (2008) show that a poverty trap can also emerge when the fraction of income spent on conspicuous consumption is decreasing with the level of human capital, which is assumed to provide a signal for individual income.

${ }^{4}$ As Azariadis and Stachurski (2005) define it, a poverty trap can be characterized by any self-reinforcing mechanism causing poverty to persist.
} 
This is why we would observe a tendency to dissave only when resources are low.

Our data give us a unique opportunity to test, for the first time, the two assumptions that can predict a low-asset poverty trap generated by self-control problems in this context $:^{5}$ In the first place, the estimation of good-specific discount rates allow us to identify the group of goods with higher discount rates. Secondly, we analyze whether the share of expenditures on these goods decreases or not with income (proxied by total expenditures) by looking at their Engel Curves. We find indeed that the Engel Curve for the share of expenditures on the three goods with higher discount rates is downwards sloping. This supports the possibility of a poverty trap in the context under study.

In this sense, the results of this paper also contribute to the literature explaining the reasons for low savings among the poor. While there is evidence around the world that the poor have room to save (Banerjee and Duflo, 2007, Collins et al., 2009), several factors have been attributed to their undersavings. Evidence of self-control problems affecting savings has been provided, for example, in relation to agricultural investments in Kenya (Duflo et al. 2010) and commitment products in the Philippines (Ashraf et al. 2006) .6 We present indirect evidence for the conditions that generate a disincentive to save due to self-control problems in the form of good-specific discount rates, which pushes the poor to protect resources from their future selves by undersaving.$^{7}$

In an ongoing field experiment we are conducting, using the same sample as in this paper, we will be able to study how having access to safe saving mechanisms interacts with selfcontrol problems in the form of good-specific discounting. In particular, we will test whether a bank account can offer enough of a commitment mechanism to reduce future consumption on high-discount goods and thereby increase saving rates among the poor.

The remainder of the paper proceeds as follows. Section 2 reviews the literature eliciting time-preferences over consumption goods, describes the surveys and the characteristics of the sample. Section 3 presents the methodology used to estimate good-specific discount rates and the main results, including a battery of robustness checks. Section 4 provides evidence

\footnotetext{
${ }^{5}$ The possibility of self-control problems leading to a poverty trap is also formalized by Bernheim et al. (1999) and (2011). However, these papers focus on the combination of time-inconsistent preferences generated by horizon-specific discounting and credit constraints.

Bryan et al. (2010) survey the literature documenting a demand for commitment devices, which is an implication of most self-control models.

${ }^{7} \mathrm{An}$ alternative mechanism that is being studied by a growing literature involves what Fafchamps et al. (2011) call a "social solidarity tax". In that case, the disincentive to save comes from the fact that resources can be appropriated either by other household members, specially from the spouse (for evidence see: Anderson and Baland, 2002 Ashraf, 2009, Schaner. 2011) or from extended family members (for recent experimental evidence see: Dupas and Robinson, 2011, Dupas and Robinson, 2012, Brune et al., 2011, Jakiela and Ozier. 2011). If the fraction of income spent to satisfy these demands decreases with income, a poverty trap can also be generated.
} 
for the Engel Curves of the high-discount goods in order to evaluate whether their share on total expenditures is or not decreasing. Finally, Section 5 includes some concluding remarks.

\section{Eliciting Good-Specific Discount Rates in the Field.}

\subsection{Related Literature}

Only a few papers have tried to test the hypothesis that the discount rate is common across goods, some in the economics literature and some in psychology. Overall, the evidence they generate is quite mixed. Psychology studies tend to find that primary rewards (those necessary for survival such as water and food) are discounted at higher rates than money ${ }^{8}$ Several studies also show that addicts have higher discount rates for their addiction than for money $!^{9}$ Finally, Tsukayama and Duckworth (2010) provide some basic evidence that individuals who report being more tempted by a particular good have higher discount rates for that good (candy, chips and beer) and a higher discount rate for those goods than for money or other goods for which they do not report being tempted. In a related study, Reuben et al. (2010) find higher discounting rates for chocolate bars than for money. While they use real payments, their sample consists of a small number of students, and they do not use equal-value rewards for the two goods (the quantities for the sooner option are 5 chocolates or 50 dollars). Therefore, their results can be due to a combination of the magnitude effect and the different value of the two goods, that is, when 50 dollars are worth more than 5 chocolates and higher-value rewards are discounted at lower rates.

It is not clear, however, how the findings from these papers would apply to poor households in developing countries. Most of these studies are based on small samples of students making choices in the lab, under hypothetical scenarios. What is more, this literature typically assumes that utility is linear in income.

The few studies based on data from the general population tend to find no evidence that time preferences vary across goods. Holden et al. (1998) find, for a sample in Zambia and using hypothetical questions, no significant differences in discount rates between cash and maize, but they have to drop a significant part of the sample due to lack of comprehension of the method used to elicit discount rates. Klemick and Yesuf (2008) do not observe significant differences in discounting for wheat, salt and cash in Ethiopia. Their study uses

${ }^{8}$ See Odum and Rainaud (2003), Green and Myerson (2004), Odum et al. (2006), Estle et al. (2007) and Charlton and Fantino (2008).

${ }^{9} \mathrm{See}$ for example Bickel et al. (2011) and references therein. 
real payments, and a two-question design to capture preference reversals. While they test for significant differences over the impatient and patient choice for the three goods, they do not have enough information to estimate good-specific discount rates. The exception is Ashraf et al. (2006) who, in a study with bank clients in the Philippines, find higher impatience levels for rice and ice-cream than for money. They do not discuss these results in the paper, however, since their focus is on horizon-specific discounting and not on good-specific discounting.

A related question is whether there are domain-general components of time preferences. Einav et al. (2010) reject the null hypothesis that there is no domain general component of risk preferences using actual choices over financial lotteries in different domains. They find high correlations across domains, but significantly different distributions of choices and no trivial evidence of context-specificity. For time preferences, Chapman (1996) finds low correlations between health and monetary choices, but similar average discount rates for the two domains. On the other hand, Reuben et al. (2010) find high correlations for discount rates elicited with monetary rewards and with chocolate, but differences in average discount rates. Both papers suggest that since the same factors affect decisions in the two domains, there could be a unique cognitive process behind both types of choices. In this direction, McClure et al. (2007) provide evidence for the existence of similar neurological processes for the discounting of primary rewards and money ${ }^{10}$

In this paper we estimate discount rates for a large list of goods in the field, using both hypothetical and real choices with a sample of more than 2,400 individuals. Moreover, we use a series of econometric estimators that allow us to check whether results persist under different modeling assumptions. We find a group of goods with significantly higher average discount rates, but at the same time, high correlations among discount rates across goods within individuals. We also see that similar factors affect discount rates across goods, including the effect of gender and the existence of a magnitude effect. This provides additional evidence for domain-general components of time preferences, but also with some context-specificity, in a similar direction as the findings by Einav et al. (2010) for risk preferences.

\subsection{Surveys Design and Sample Characteristics}

We designed and conducted two surveys with modules to elicit time preferences. The first one has the goal to elicit discount rates for a large list of consumption goods using hypothetical

\footnotetext{
${ }^{10}$ They replicate using juice and water the findings by McClure et al. (2004) for monetary incentives. In their first study they show that the limbic reward-related areas in the brain are primarily activated when individuals make decisions involving immediate rewards, while the lateral prefrontal cortex is activated both by decisions involving short and long term rewards.
} 
choices; while the second one uses real rewards to check for the robustness of results with a smaller set of goods and it includes additional questions to control for factors potentially affecting the elicitation procedure.

\subsubsection{First Survey}

The first survey was conducted with a sample of 2,442 individuals in a rural region of Central Uganda, who where visited at home between October and November, 2010. Time-preference questions for nineteen goods were asked at the beginning of a long background survey. A census performed in June, 2010 found 9,287 households in the area and 3,000 of them were randomly selected for the baseline survey; for 2,442 households one of the heads or the single head was successfully interviewed.

The area under study is mainly rural and poor, Table 1 describes the sample. Most of the households are low-scale farmers, $85 \%$ farm at least one crop and $65 \%$ sell at least one crop. The median plot size is 1 acre, the median value of crops sold for the last harvest is around 10 dollars, and investments in agricultural inputs are low, with only $10 \%$ using fertilizer. The majority of the respondents are female, with less than 6 years of education on average (the minimum to complete elementary school is 7 years); almost a quarter of the sample cannot read or write in Luganda, the local language, and correct responses both in a digit recall memory test and a Raven's matrix cognitive test are around $50 \%$.

From a series of interviews with local households, we constructed a list of nineteen locally available goods.11 In order to elicit good-specific discount rates, we adapted the questions for monetary rewards by Coller and Williams (1999) ${ }^{12}$ Similar questions have been used to elicit discount rates with monetary rewards in developing countries 13

Subjects were faced with five paired choices between smaller rewards that would be received the same day and larger rewards that would be received in one month. Questions were designed to maximize respondent's understanding and to distinguish high differences in discount rates across goods. For example, respondents had the option to choose between 1 kilo of sugar now and 1.5 kilos of sugar in a month. If they chose the sooner option, they were asked for their preference between 1 kilo now and 2 kilos in a month, and the delayed quantity was increased until they switched ${ }^{14}$ These questions were based on hypothetical

\footnotetext{
${ }^{11}$ Besides money (the standard good used in the literature to elicit time preferences), the list includes: beans, matooke (green plantain and main staple), salt, sugar, soda, meals at restaurants, snacks, alcohol, bar games, clothes, lotion, perfume, entertainment, hairdresser salon, cellphone airtime, meat, school supplies, and shoes.

${ }^{12}$ For a detailed critical review of the recent literature eliciting time preferences see Andersen et al. (2011a).

${ }^{13}$ See, among others, Dupas and Robinson (2009), Bauer et al. (2010), Shapiro (2010) and Schaner (2011).

${ }^{14}$ We assume monotonicity in responses (e.g. if respondents prefer 2 kilos of sugar in a month to 1 kilo now, they would also prefer 3 kilos in a month to 1 kilo now).
} 
choices; while respondents were encouraged to reveal their preferences as if their choices were real, no real incentives were provided.

We used "equal-value" trade-offs across goods, with the sooner choice given by a number of units with an approximate cost of 2,500 Ugandan Shillings. ${ }^{15}$ For each good, the ratios between the sooner and each possible delayed choice are the same, in order to avoid possible framing effects affecting the estimation of discount rates. Units were chosen not to be too large to generate satiation and not too small to make choices irrelevant in relation to typical consumption patterns. We also asked two additional sets of questions for each good including lower and higher quantities in order to control for possible magnitude effects that will prove to be significant.

\subsubsection{Second Survey}

The second survey was performed between August and September, 2011. The sample was constructed as a random subsample of 500 individuals taken from the 2,442 individuals in the first survey, out of which 449 respondents were found and interviewed. Summary statistics for this sample are presented in the second panel of Table 1. There is no evidence of statistically significant differences in any of the variables with respect to the full sample.

The survey consisted of time preferences questions to elicit discount rates for six goods and a series of questions to better understand the factors behind those choices. The quantity of each good was adapted to reflect changes in relative prices, but questions followed the same format as the one in the first survey. The exception is that we used two sets of questions representing "equal value" trade-offs ${ }^{16}$ one with smaller and one with larger quantities. ${ }^{17}$

In this case, respondents were told that one of the choices would be paid for real and that, for each good, every answer would have the same probability of being chosen. At the end of the survey, each respondent drew a piece of paper from a bag containing the names of the six goods, and then another piece of paper from a second bag to determine the question to be paid among the ones they answered. To minimize differential uncertainty and transaction costs between the sooner and the delayed payment, respondents were told that in the case that the sooner reward was picked, an enumerator would come back to their house at the end of the day with the payment. If the delayed reward was picked, an enumerator would come back with the payment in one month. In both cases, respondents were given a

\footnotetext{
${ }^{15}$ The exchange rate at the time of the first survey was 2,290 Ush per dollar. Since before the first survey data on local prices were not widely available, some of the resulting monetary values of the goods turn out to be greater than $2,500 \mathrm{Ush}$. This did not affect our conclusions.

${ }^{16}$ The sooner choice involved a number of units with an approximate cost of 3,000 Ush, being the exchange rate 2,590 Ush per dollar at the time of this survey.

${ }^{17}$ In this case, seven choices instead of five were presented for each good, including a first one to capture discount rates equal or lower than 0 .
} 
certificate with the logo and signature of the NGO we worked with. Respondents had already participated in the initial census and background survey, and in each case they signed an informed consent in which they were told that new interviews would be performed in the following year. Therefore, they were in general familiar with the NGO and trust issues were not a significant problem, as indicated by self-reported trust measurements included in the survey.

\section{$3 \quad$ Econometric Methods and Results}

\subsection{General Framework}

In this section we describe the general framework we use to elicit discount rates based on the time-preference questions. A subject choosing between option A offering $M_{0 j}$ units of good $j$ in $t=0$ and option $\mathrm{B}$ offering $M_{1 j}$ units in $t=1$ will be indifferent between the two payment options if and only if the present value of the two options is the same:

$$
U_{0 j}\left(b_{0 j}+M_{0 j}\right)+D_{j}(1) U_{1 j}\left(b_{1 j}\right)=U_{0 j}\left(b_{0 j}\right)+D_{j}(1) U_{1 j}\left(b_{1 j}+M_{1 j}\right)
$$

where $b_{j}$ is a measure of background consumption for good $j$ (quantity integrated into the utility with the reward), $U_{j}$ is the utility function and $D_{j}$ the discount function. In order to be able to identify good-specific discount rates with our data, we assume a time-separable utility function and non-complementarity in consumption across periods and across goods. 18

To identify discount rates using equation (1), we need to impose some additional modeling assumptions. ${ }^{19}$ Most of the papers mentioned in Section 2.1 assume linear utility function, zero background consumption and are based on hypothetical rewards. Andersen et al. (2011a) show that relaxing these assumptions can weaken the evidence for hyperbolic discounting presented in the literature. Our results on good-specific discounting persist even after taking these factors into account.

We first follow the basic procedure in the literature assuming linear utility, zero background consumption and using hypothetical rewards. We abstract from the possibility of

\footnotetext{
${ }^{18}$ The separability over time is an assumption typically adopted in the literature. It rules out, for example, models of addiction and habit formation, which could provide an alternative explanation for our results if they are based on good-specific parameters. The separability across goods is a strong assumption added to estimate good-specific discount rates. In future research it would be possible to release this assumption by estimating a more general utility function that captures complementarities across goods.

${ }^{19} \mathrm{An}$ additional important assumption is the inexistence of markets to re-allocate the goods under analysis (or at least that respondents do not take trade opportunities into account when performing the timepreference tasks). We provide some evidence in this direction. If there were perfect markets, we would need extra assumptions, such as equal marginal rates of substitution across goods.
} 
horizon-specific discount rates to focus on testing for good-specific discounting. ${ }^{20}$ We first control for the curvature of the utility function by jointly estimating a single risk aversion parameter and good-specific discount rates, and we also allow for different measures of background consumption. We then check whether our conclusions hold when choices are made under real incentives. Finally, we control for good-specific factors that might act as confounding factors in the elicitation of discount rates.

\subsection{Do We See Differences in Discount Rates Across Goods?}

\subsubsection{Basic Procedure}

We first follow the typical assumptions in the literature, that is: linear utility function and zero background consumption. If we impose an exponential discount function allowing for a good-specific parameter, equation (1) simplifies significantly and we can solve for the discount rate $\rho_{j}$ for each good in the following way:

$$
M_{o j}=\frac{1}{1+\rho_{j}} M_{1 j} \Longrightarrow \rho_{j}=\frac{M_{1 j}}{M_{0 j}}-1
$$

We compute discount rate bounds for each individual, each good and each choice using equation (2). As an initial step we assign to the value of the discount rate the midpoint of the interval implied by the question at which the respondent switches to the delayed option. The following table describes the implied bounds for each choice and the imputed discount rate:

\begin{tabular}{|c|c|c|c|c|}
\hline Choice & $M_{o j}$ & $M_{1 j}$ & Implied Bounds if Respondent Chooses $M_{1 j}$ & Discount Rate \\
\hline \hline 1 & 1 & 1.5 & {$[0,0.5)$} & 0.25 \\
\hline 2 & 1 & 2 & {$[0.5,1)$} & 0.75 \\
\hline 3 & 1 & 2.5 & {$[1,1.5)$} & 1.25 \\
\hline 4 & 1 & 3 & {$[1.5,2)$} & 1.75 \\
\hline 5 & 1 & 3.5 & {$[2,2.5)$} & 2.25 \\
\hline
\end{tabular}

Since the ratios between the sooner and the delayed rewards are the same for all goods and all quantities, each choice implies exactly the same discount rate for each good. For example, the second choice for sugar is between 1 kilo today and 2 kilos in a month (or 3 kilos and 6 kilos for large quantities), while the one for meat is between 0.5 kilos today and 1 kilo in a month (note that both 1 kilo of sugar and half a kilo of beef are worth approximately $2,500 \mathrm{Ush})$. If the respondent switches at the second choice for either of the goods, we assign

\footnotetext{
${ }^{20} \mathrm{~A}$ topic for future work is to study whether the results on horizon-specific discounting using monetary payments still hold for consumption goods.
} 
a discount rate of 0.75 for that good 21

Another important point is that the imputed rate for those switching at the first option is already very large, a $25 \%$ monthly discount rate. This will be our baseline to compare all other discount rates when we assume linear utility. Moreover, this implies that we will not be able to identify differences in discount rates across goods for those individuals having low discount rates for all goods. Nevertheless, the fact that we do identify significant differences across goods means that these differences are large. ${ }^{22}$

Table 2 presents summary statistics for discount rates calculated with this basic procedure. We can see that there are three goods: sugar, matooke and meat with significantly higher average discount rates, and in particular, significantly higher than the one for money. Furthermore, we can see that the median individual has a discount rate of 0.75 for these three goods, implying a switch at the second option. Whereas, for all the other goods the median individual switches at the first option, and has an imputed discount rate of 0.25.23

\subsubsection{Basic Procedure, Pooled Estimation}

In order to test whether differences in average discount rates are statistically significant and to take into account that the same individuals are providing answers across goods, we estimate a pooled regression, clustering standard errors at the individual level. In a similar approach to the one used by Shapiro (2010), who tests for differences in discounting when individuals choose in groups or individually, we use good-specific dummies (using money as the omitted category) to test for differences in discount rates across goods. We estimate:

$$
\rho_{i m g}=\beta_{0}+\sum_{g=1}^{n} \beta_{g} \mu_{g}+\varepsilon_{i m g}
$$

where $\rho_{i m g}$ is the discount rate (calculated following the basic procedure described in 3.1.1) of individual $i$, for the question of amount $m$ and good $g$. The goal is to estimate the coefficients $\beta_{g}$ on the good effects $\mu_{g}$, being money the omitted category. The estimates for the coefficients $\beta_{g}$ can be interpreted as the average difference between the individual

\footnotetext{
${ }^{21}$ We assume non-negative discount rates, which gives us a lower bound of 0 . In order to get an upper bound we assume that if the respondent chooses the sooner option for all choices, the discount rate will be one interval larger, that is 2.75 . Our results are robust to dropping the individuals always choosing the sooner option, who represent approximately $14 \%$ of our sample.

${ }^{22}$ In order to estimate more precisely the level of discount rates we would have had to offer additional tradeoffs to reduce the length of the intervals. This would have introduced extra complications for respondents that we preferred to avoid in order to maximize their understanding and response rates.

${ }^{23}$ We do not present results for beer and bar games since more than $50 \%$ of respondents refused to answer the questions on the basis of religious reasons. The discount rates calculated for those who did answer are in the range of the ones for the low-discount goods.
} 
discount rate applied to good $g$ and the one applied to money.24

Results from estimating equation (3) can be seen in Table 3. Column (1) presents results for discount rates calculated using the "equal-value" questions in order to avoid the noise from using magnitudes with different value across goods. Only for meat, sugar and matooke the estimated coefficients are positive and highly significant, indicating higher average discount rates for these goods than for money. In Column (2) we use discount rates calculated using all questions, including those with different magnitudes. In this case we include two indicators for questions with equal-value trade-offs (Equal Value) and small-value trade-offs (Small) to control for magnitude effects. The omitted category is large-value trade-offs, which implies trade-offs between larger quantities than the previous two cases. Differences are reduced, but only for the same three goods the coefficients are positive and statistically significant.

The coefficients on the Small Quantities and Equal Value question dummies at the bottom of Column (2) imply that larger rewards, the omitted category, are discounted at significantly lower rates. This provides evidence for a magnitude effect for monetary rewards. We find that the same effect applies to each of the goods in our list, and it is robust to different modeling assumptions. This is a unique finding of our paper; while evidence for lower magnitudes being discounted at higher rates has been provided by a large number of articles, none of them uses real consumption goods and real rewards ${ }^{25}$

Finally, by running interval regressions for each good we confirm that the results still hold if we follow a data-driven procedure to choose one point of the discount rates interval instead of arbitrarily using the midpoint. Column (3) presents differences in predicted discount rates for each good and money obtained by estimating interval regressions for each good. An interval regression is equivalent to an ordered probit model with fixed cutpoints in which the two bounds of discount rates intervals are used as dependent variable. We estimate by maximum likelihood one equation for each good using the equal-value questions, with only a constant as explanatory variable and we take the coefficient of the constant as the corresponding predicted value. When comparing the differences in predicted discount rates obtained with this method with those presented in Column (1), we find similar values,

\footnotetext{
${ }^{24}$ While choosing money as the baseline category is arbitrary, we do this taking into account that the results in the time-preference literature are based on monetary rewards. Moreover, by showing differences with respect to money, we are also proving that there are differences with respect to all the other goods in our list since they exhibit lower discount rates than money.

${ }^{25}$ See Frederick et al. (2002) for a list of papers. Chapman (1996) finds magnitude effects both for money and health, but uses only hypothetical choices. Andersen et al. (2011b, b) present a critic review including problems that make the evidence for the magnitude effect in the literature at least questionable. After controlling for different modeling assumptions, they show that the magnitude effect is still present, but with a smaller magnitude than usually found, and disappears when choices involve a time delay. While we do not include time delays, we follow similar methodologies as in their paper and we still find large magnitude effects.
} 
indicating that taking the midpoint is not determining our results.

\subsection{Are the Differences Across Goods Robust?}

\subsubsection{Controlling for the Curvature of the Utility Function: Joint Elicitation Procedure}

Most of the papers estimating discount rates described in the survey by Frederick et al. (2002) assume a linear utility function, but Andersen et al. (2008) highlight the importance of performing a joint estimation of the shape of the utility function and the discount rate. By Jensen's inequality, the implied discount rate will be lower if utility is concave in rewards than if it is assumed to be linear. The concavity of the utility function might not only affect the levels of discount rates, but also the differences across goods ${ }^{26}$ We show that while the former is observed in our data, the differences we find across goods are still consistent with the results from the previous section.

We perform a maximum likelihood estimation of a model that follows the general latent choice process specification by Andersen et al. (2008). We jointly estimate a single risk aversion parameter and good-specific discount rates ${ }^{27}$ We measure utility curvature by assuming a constant relative risk aversion utility function only as a convenient vehicle to estimate the non-linear utility function of the individua ${ }^{28}$ and we elicit the single risk aversion parameter from two sets of questions on preferences over lotteries.29

The estimation is based on a two-part likelihood function. The first part makes use of the risk-preference questions to estimate a single risk aversion parameter $r$, which we use for all goods. Given that our risk questions involve choices between two lotteries with two equal-probability outcomes, we can write the expected utility for each lottery $i=A$, $B$, with

\footnotetext{
${ }^{26}$ For example, if we derive equation (2) using a CRRA utility function with a risk aversion parameter between 0 and 1, and we follow the same basic procedure taking the midpoint of the interval, we will see that the implied discount rates are lower, and the differences in discount rates between two given choices are also reduced.

${ }^{27}$ While we would like to elicit good-specific risk aversion parameters, this was not feasible for the current study given the difficulty involved in the required tasks, the low educational levels in our sample, and the time restrictions of field interviews. Procedures like the ones used in Andreoni and Sprenger (2010) or Laury et al. (2011) to elicit curvature-controlled discount rates could be used in future work. The former remarks the importance of making the budget set continuous. Andreoni et al. (2012) develop an extension that can be used in the field.

${ }^{28}$ For a detailed review of the methods and literature to elicit risk preferences see Harrison and Rutstrom (2008).

${ }^{29}$ In the first one, respondents were asked to imagine that they could invest up to 1,000 Ush in a small business, which would yield 2.5 times the amount invested half of the time, and 0 the other half of the time. They had to choose whether to invest $0,200,400,600,800$ or 1,000. The second task was similar, but they were told that they could invest up to 3,000 Ush.
} 
outcomes $M_{0 i}$ and $M_{1 i}$ and background consumption $b$ as:

$$
E U_{i}=0.5 \frac{\left(b+M_{0 i}\right)^{1-r}}{1-r}+0.5 \frac{\left(b+M_{1 i}\right)^{1-r}}{1-r}
$$

The probability of choosing lottery B for each choice is defined in the model as:

$$
P_{r}^{R}(B)=\frac{E U_{B}^{1 / \mu}}{E U_{A}^{1 / \mu}+E U_{B}^{1 / \mu}}
$$

where $\mu$ is a behavioral or structural noise parameter that reflects possible errors in the expected utility model ${ }^{30}$ We define a dummy variable $y_{i}=1(0)$ if lottery $B(A)$ is preferred for choice $i$, and $I$ is an indicator function. The first part of our conditional log-likelihood function is:

$$
\ln L^{R}(r, \mu, y, b)=\sum\left[\ln P_{r}^{R}(B) * I\left(y_{j}=1\right)+\ln \left(1-P_{r}^{R}(B)\right) * I\left(y_{j}=0\right)\right]
$$

Similarly, we construct the second part of the likelihood function by using the timepreference choices. Equation (9) presents the probability index, and the present value for the sooner option $A$ and the delayed option $B$ are given for each good $j$ by equations (7) and (8):

$$
\begin{gathered}
P V_{j A}=\frac{\left(b_{j}+M_{o j}\right)^{1-r}}{1-r}+\frac{1}{1+\rho_{j}} \frac{\left(b_{j}\right)^{1-r}}{1-r} \\
P V_{j B}=\frac{\left(b_{j}\right)^{1-r}}{1-r}+\frac{1}{1+\rho_{j}} \frac{\left(b_{j}+M_{1 j}\right)^{1-r}}{1-r} \\
P_{r j}^{D}=\frac{P V_{j B}^{1 / \varepsilon_{j}}}{P V_{j A}^{1 / \varepsilon_{j}}+P V_{j B}^{1 / \varepsilon_{j}}}
\end{gathered}
$$

Then, the conditional log-likelihood function for time-preference choices is given by:

$$
\ln L_{j}^{D}\left(r, \rho_{j}, \mu, \varepsilon_{j}, y_{j}, b_{j}\right)=\sum\left[\ln P_{r}^{D}(B) * I\left(y_{j}=1\right)+\ln \left(1-P_{r}^{D}(B)\right) * I\left(y_{j}=0\right)\right]
$$

The joint conditional log-likelihood function for good $j$ (conditional on CRRA, exponen-

\footnotetext{
${ }^{30}$ This specification was used by Andersen et al. (2008), Coller et al. (2011) and Laury et al. (2011) in the discounting literature, but it is only one possible specification of errors. Andersen et al. (2011a) also use an alternative specification of errors in which the probability of choosing lottery B is defined as the difference in expected utilities and then a cumulative distribution function is used to link it to observed choices. When we follow this alternative specification our results converge only when we introduce the contextual error correction suggested by Wilcox (2011), in this case we get similar conclusions. Results are available upon request.
} 
tial discounting and expected utility), combines equations (6) and (10):

$$
\ln L_{j}\left(r, \rho_{j}, \mu, \varepsilon_{j}, y_{j}, b_{j}\right)=\ln L^{R}+\ln L^{D}
$$

Table 4 presents the estimates for the good-specific discount rates from maximizing (11) for each good. We can see in Column (1) that while the level of the estimated discount rates is lower than when we assume linear utility, as expected, the conclusion in terms of differences across goods still holds. We see again that matooke, sugar and meat are the three goods to which higher discount rates are applied. By looking at the the $95 \%$ confidence interval bounds for these estimates presented in Columns (2) and (3), which were calculated using standard errors clustered at the individual level, we can see that the differences in discount rates between these three goods and all the other goods are statistically significant.31

We next allow for individual heterogeneity by letting the risk aversion and discount rate parameters be a linear function of observable characteristics. We include dummy variables for gender, being married, being literate and having an ability score (measured by a Raven's matrix test) lower than the average. The predicted mean discount rates are similar to the ones estimated without controls and the differences across goods are still statistically significant. We find that having a low ability score and being a woman significantly increase risk aversion, while the other covariates are not significant. Only gender significantly affects the discount rates. Column (4) in Table 4 presents the predicted discount rate for females based on the coefficient obtained when we allow both the discount rate and risk aversion parameters to depend on observable characteristics. We can see that women have significantly lower discount rates for each of the goods (except for saloon visits for which the difference is positive, but not significant), but the ranking of discount rates across goods is the same for women as for the full sample. Andersen et al. (2011a) also find that the only covariate with statistically significant impact on discount rates elicited with monetary rewards is gender, with an effect in the same direction as in our case. This derives from women being more risk averse, which means that they have a more concave utility function and a lower implied discount rate by Jensen's inequality. In contrast, Bauer and Chytilova (2009) use data from Uganda as in our case and find that women have higher discount rates (except for the

\footnotetext{
${ }^{31}$ These estimations assume zero background consumption. We also estimate $r=0.13(0.01)$, and the structural errors as $\mu=0.09(0.01)$ and $\varepsilon=0.38(0.01)$. The risk aversion parameter is low in comparison to other results from the literature, but we still find risk averse agents. The fact that the errors for the discount choices are higher than the ones for the risk choices might be due to the larger number of choices for each good in the former case. The different number of observations in Column (5) of Table 4 is due to missing values for some households not giving responses for some of the choices. The number of missing choices is low for the goods presented in the table, being the maximum $0.9 \%$ for perfume. We do not present results for beer, bar games and entertainment since large percentages of the sample refused to reveal their choices for these goods.
} 
youngest and with medium level of education). The key difference is that they do not control for differential risk aversion between men and women.

As robustness checks we also include controls for small-quantity and equal-value questions, and we find that the magnitude effect is present for all goods, but we still derive the same conclusions in terms of differences across goods. Finally, we pool choices over all goods and include dummy variables for each good, except for money. Our findings replicate the ones in the pooled estimation, with only matooke, sugar and meat showing positive and significantly higher discount rates 32

\subsubsection{Discount Rates Elicited with Real Incentives}

There is a significant discussion in the literature on whether the use of hypothetical payments instead of real payments can generate a bias in discount rates. In order for this potential bias to be relevant for our study, it has to be the case that respondents fail to reveal their true preferences with hypothetical rewards and that this behavior differs by good.

The evidence on whether the use of real or hypothetical monetary rewards makes a difference is mixed. On the one hand, a series of papers argue that similar results are found in the two cases or that there is at least no evidence for significant differences (Frederick et al. 2002, Green and Myerson, 2004, Benhabib et al., 2010, among others). On the other hand, Steffen Andersen, Glenn Harrison and coauthors claim that the evidence is "overwhelming that there can be huge and systematic hypothetical biases" (Andersen et al., 2011a, pp. $37) 33$

We test whether results obtained with hypothetical rewards differ from those found with real incentives. In our second survey we performed a new set of time-preference questions for six of the goods used in the first survey and one question was randomly chosen for payment. The goods for which we replicated the questions were the three ones for which we had found high discount rates with hypothetical rewards: matooke, sugar and meat 34 the standard good used in the literature: money; and two goods for which we had found low discount rates: school supplies (as we expected since people mention wanting to save for them) and cellphone airtime (for which we expected ex-ante to see high discount rates).

Table 5 replicates Table 1, but it now restricts the observations to the 449 households interviewed again in the second survey. By comparing the two panels of Table 5, we can

\footnotetext{
${ }^{32}$ Results are available upon request.

${ }^{33}$ Outside the discounting literature the debate is similar, with some papers concluding that there is not enough evidence for hypothetical biases, and others disagreeing (see for example Harrison and Rutstrom. 2008).

${ }^{34}$ This question was specific about beef, while in the previous survey it was about meat in general (but most people had answered thinking about beef according to evidence from the field). Therefore, we will use beef and meat interchangeably throughout the paper.
} 
appreciate that there is no statistically significant difference in discount rates for any of the six goods when we compare discount rates elicited with hypothetical or real rewards (confidence intervals overlap in all cases). This result also implies that there is no evidence to reject the null that average discount rates remain constant over the period of one year.

We still see that matooke, sugar and meat are the three goods with significantly higher discount rates (although the standard errors are now larger due to a smaller sample size, differences are still significant at the $10 \%$ level). The same conclusion is derived when we compare discount rates obtained with real rewards for these three goods and with hypothetical rewards for the others, or the other way around.

In Table 6, we present results for a pooled estimation with the new data. We can see in Column (1) that the same results hold, and when we cluster the standard errors at the individual level all differences become largely significant. In Column (2) we present results using both "small quantity" and "large quantity" questions. In this survey, the two sets of questions represent the same monetary values across goods, so it is not problematic to combine them. The differences are increased, but the main conclusions remain the same. Moreover, the "small quantity" question dummy is positive and statistically significant confirming the magnitude effect mentioned above.

\subsubsection{Controlling for Good-Specific Factors}

The use of hypothetical rewards, the curvature of the utility function and framing effects (such as presenting respondents with choices of different values) are factors usually mentioned as potential confounds when attempting to measure discount rates (Frederick et al., 2002, Chabris et al., 2008). As Reuben et al. (2010) note, there are other additional complications when we want to estimate discount rates for real consumption goods. Among them, the possibility of good-specific factors confounding the elicitation of discount rates.

In the second survey we asked respondents about factors influencing their choices between the sooner and delayed reward for each good. Column (3) of Table 6 presents the results for the pooled regression when we also include dummy variables for four factors that may act as potential confounds for the discount rates. These variables take the value of one when respondents answer positively about the factor determining their choice for the particular good: $\$ 55$ the capacity to store large outcomes (Storage), the possibility of reselling the good (Resale), the expected price in one month in comparison to current price (Price) and the uncertainty about receiving payments in the future (Uncertainty). Since the questions were

\footnotetext{
${ }^{35}$ For example, the variable Storage takes the value of 1 in the rows of data corresponding to matooke if the respondent mentions that storage was a relevant factor when making choices about matooke, and it can also take the value of 1 for the rows of sugar if it was mentioned as a relevant factor for choices with sugar.
} 
asked for each good (when applicable), they are person and good-specific, thus the regression uses both variation across goods and within individual, and we control for individual fixed effects. The effects on average discount rates are positive for Uncertainty and Storage. They are negative, although not significant, for Price and Resale 36 Nevertheless, the differences in discount rates are practically unaffected when we include these four factors in the pooled regression.

In Column (5), we see that differences in discount rates across goods persist even when we allow for interactions between each of these factors and the good-specific dummies. ${ }^{37}$ The differences in discount rates for matooke, beef and sugar cannot be attributed to these four confounding factors since the coefficients on the dummies for each of these goods remain significantly different from zero even after including the interactions with the potential confounders. However, some of the confounding factors did contribute to find even larger differences across goods. In the case of matooke and sugar, an increase in discount rates was linked to differential uncertainty about future payments (although only $6 \%$ of respondents mention this factor for these goods, $3 \%$ did so for money). For beef, storability appears to be a factor correlated to higher discount rates, but as expected, only for large quantities (when we restrict results to small-quantity questions the interaction is no longer significant).

Finally, we also asked about two factors that we expected ex-ante to be correlated with discount rates if these are truly reflecting time-preferences: the desire to have the good the same day and the desire to have the good in a month. In Column (4) of Table 6 we can see that people mentioning their desire to have the good the same day as a relevant factor have significantly higher discount rates for that good and those mentioning their desire to have the good in a month significantly lower discount rates. As we expected, the coefficients on the good dummies are now reduced.

Table 7 replicates the jointly elicited coefficients in Table 5 with real rewards. By looking at the maximum likelihood estimates and the corresponding 95\% confidence intervals in Column (1) to (3), we can see that our conclusions in terms of differences across goods still hold. We have a group of goods with high discount rates: sugar, beef and matooke; and another group with relatively lower discount rates: money, airtime and school supplies (the difference between matooke and beef is almost significant at the $10 \%$ level). This time we also included the good-specific factors discussed above. As we can see from Column (6) to (11),

\footnotetext{
${ }^{36}$ On average, only $7 \%$ of the sample mention resale opportunities as a relevant factor for their choice. This might indicate that arbitrage opportunities across goods are not significant in our sample. Moreover, capital markets are underdeveloped in the area and credit is very scarce with only $12 \%$ of people reporting requests for loans from a bank or microfinance institution.

${ }^{37}$ For example, the variable Storage*Matooke takes the value of 1 when the individual mentions storage problems for matooke and zero in all the other cases.
} 
where we use data for both small-quantity and large-quantity questions of equal value across goods, the only confounding factor that significantly affects discount rates is the uncertainty about future payments, with a positive sign as expected. However, even after controlling for these potential confounders in Column (5), the rank across goods is preserved. Finally, Columns (10) and (11) show that the desire to have the good the same day or in a month is significantly correlated with discount rates for all goods and with the correct signs. This suggests that we are actually capturing time preferences, and not the effect of confounding factors.

\subsubsection{Allowing for Non-Zero Background Consumption}

The assumption of zero background consumption is standard in the literature, but both Andersen et al. (2008) and Andreoni and Sprenger (2010) show that estimated discount rates can be sensitive to the value of background consumption, highlighting the importance of incorporating it in the estimation. In addition, elicitation procedures usually assume completely constrained subjects who consume the sooner or delayed reward at the time stated and do not smooth consumption over time. In order to release these assumptions, we allow for $b_{j}$ being different than zero in the joint estimation procedure (see equations (6) and (7)) with real rewards, since we included specific questions to measure background consumption in the second survey.

The first point to consider is how to measure background consumption, the amount that is integrated with the reward and evaluated in the utility function. Andersen et al. (2008) define it as the optimized consumption stream that is perfectly anticipated before allowing for the rewards, and they assume a single value for all individuals in their sample equal to the average per capita daily consumption of private non-durable goods. In our case, we have data to make this parameter person-specific. Our first approximation identifies background consumption with the amount of each good that individuals have at home (or available) at the moment of the survey, we call it Background 1. Our second approximation, Background 2 , allows for different values in the present and in one month. ${ }^{38}$ It also uses the answers to a question asking how much of each good respondents expect to have at home in a month. We can see in Table 8 that the discount rates estimated using these assumptions for background consumption are similar to the ones in Table 7 obtained under zero background consumption for our first measure (Background 1). The estimates change considerably under our second measure (Background 2), where they are less precisely estimated probably due to the noise in

\footnotetext{
38 Andreoni and Sprenger (2010) also allow for the two parameters to differ, but they estimate them as endogenous variables in their model. See Noor (2009) for the possible implications of time-varying background consumption.
} 
reported expected background consumption 39 But, in the two cases the ranking of discount rates across goods is preserved, although the differences become insignificant in the second case.

The second estimation issue is the period over which rewards are integrated with background consumption. Andersen et al. (2008) divide rewards evenly over $\lambda$ periods of time for the discounting choices, and integrate a fraction $1 / \lambda$ with background consumption. This parameter $\lambda$ can be interpreted as the time horizon over which the subject is optimizing. The usual assumption in the literature is $\lambda=1$, which implies that subjects do not smooth consumption over time, that they are completely liquidity constrained and consume the monetary amounts at the time stated in the instrument. While Andersen et al. (2008) change $\lambda$ arbitrarily, assuming a unique value across their sample, we use proxy variables for it based on our data. In particular, when $b_{j}$ is the amount of the good consumed in a day, $\lambda$ is the number of days over which the subject expects to consume the quantity of the good received as reward. We first calculate daily consumption for each individual from data on consumption of each good in a typical month and we use this value as $b_{j}$, we also asked respondents about the period over which they would consume the rewards for matooke, beef and sugar, and we use their answers to calculate $\lambda$ for each individual (the averages were 6 days for matooke, 7 for sugar and 2 for beef). Results are presented in the rows for Background 3 in Table 8; they are similar to those using Background 1 and consistent with our previous estimations. Finally, using the same procedure to get $b_{j}$, we defined $\lambda$ as the ratio between reported typical monthly consumption for each good and the amount of each good potentially received as reward. Results are presented in the rows for Background 4. Discount rates are higher for all goods in this case, but differences between matooke, sugar and beef on the one side, and school supplies, money and airtime on the other, become statistically significant again.

\subsubsection{Effect of Demographic Characteristics}

We find that approximately $50 \%$ of our sample exhibit higher discount rates for sugar, beef or matooke than for money; and $22 \%$ higher rates for the three goods than for money. This provides evidence both for context specificity and for some general components of time preferences since discount rates are statistically the same across goods for the other $50 \%$ of the sample.

Considering that the results presented in the pooled estimations control for individual fixed effects, we can claim that the differences we observe in discount rates across goods are

\footnotetext{
${ }^{39}$ This might be related to the explanation by Soman et al. (2005) pointing that individuals overestimate the availability of the good in the future (underestimating their future constraints).
} 
not driven by individual characteristics that are the same across goods. On the other hand, the joint elicitation procedure estimates an average discount rate for each good, which can depend on demographic characteristics.

As we have mentioned before, we find that gender significantly affects the estimated discounts rates in the joint elicitation, with women having higher risk aversion and lower discount rates. However, as we have seen in Table 4 (see also Column (4) of Table 7), we find that the ranking across goods is preserved even for women. In order to also allow for heterogeneity of responses not captured by observable characteristics, we follow Andersen et al. (2008) in estimating random coefficients by Simulated Maximum Likelihood. The risk aversion parameter and the discount rate (for each good) are considered random coefficients, and a bivariate Normal distribution is assumed for the two of them. 40

The estimated means for the discount rates are all very similar (and statistically indistinguishable) to those of the previous maximum likelihood estimates that assumed zero standard deviation. The estimated standard deviations for the discount rates of matooke, school supplies, money and airtime are not significantly different from 0 , while the ones for beef and sugar are only significant at the 10\% level. Furthermore, we cannot reject the hypothesis that the standard deviation of discount rates is the same for all goods, and we still find the same significant differences in the means as before.

\subsection{Why Differences in Discount Rates Across Goods? Qualita- tive Discussion.}

As some of the early twentieth century economists argued, time preferences can be the result of diverse psychological motives (see the discussion in Frederick et al., 2002). We do not find evidence to determine particular motives that may lie behind the differences in discount rates across goods in our sample. We included self-reported impulsivity measures and found the highest values for sugar and matooke, but also high values for phone airtime. Moreover, these measures are not correlated with the discount rates. On the other hand, as reported in Section 3.3.3, we see a strong correlation between discount rates and the self-reported questions about the desire for the good the same day or in a month. These questions might reflect an approximation to "pure" time-preferences, which validates our elicitation procedure.

We can say that matooke, sugar and beef are relatively expensive sources of calories for

\footnotetext{
${ }^{40}$ We simulate the likelihoods for random draws (using Halton sequences of uniform deviates) from this distribution and we average over these simulated likelihoods. In future work it would be important to allow for more flexible distributions, like the Logit-Normal used by Andersen et al. (2011a), in order to allow for non-symmetric distributions.
} 
households in the area. With a back of the envelope calculation, ${ }^{41}$ we find that beef is the most expensive source of calories, with a cost per kilo-calorie absorbed of 2.67 Ush. For matooke $e^{42}$ and sugar the cost is 0.97 and 0.64 Ush respectively, more expensive than beans or rice (0.58) and maize flour (0.24) that are also available in the area. An alternative source of proteins than beef is groundnuts, with cost per kilo-calorie absorbed of 1.28. Nevertheless, these three goods add up to $47 \%$ of expenditures in our list of goods, which in turn represent $57 \%$ of total non-durable expenditures reported in the background survey.

At least part of these expenditures might be reflecting the existence of self-control problems. In the next section, we apply these results to a model that explain how self-control problems generated by good-specific discounting can interact with poverty. There are some biological explanations on why people might be more impatient for high-sugar and highstarch food (such as matooke) than for other goods, and that these impatience levels might be correlated with self-control problems ${ }^{43}$ We abstract from the causes of the differences and focus on the consequences of observing good-specific discount rates.

\subsection{Summary of Results}

Our estimation of good-specific discount rates led us to reject the hypothesis that discount rates are equal across all goods. We identified a group of three goods for which people in our sample are on average more impatient. The following table presents a summary of our results for the differences between sugar and money (similar conclusions can be derived for matooke and meat):

\begin{tabular}{|c|c|c|c|c|}
\hline Method & \multicolumn{2}{|l|}{ Pooled Estimation } & \multicolumn{2}{|l|}{ Joint Estimation } \\
\hline Assumption & Difference Sugar-Money & Money & Difference Sugar-Money & Money \\
\hline Risk Neutrality (Table 3, col. 1) & $0.13^{* * *}$ & 0.90 & & \\
\hline Risk Aversion (Table 4, col. 1) & & & $0.18^{* * *}$ & 0.36 \\
\hline Non-Zero Background C (Table 8, row 1) & & & $0.28^{* * *}$ & 0.45 \\
\hline Real Rewards (Table 6, col. 1, Table 7, Col. 1) & $0.22^{* * *}$ & 0.88 & $0.20^{* * *}$ & 0.42 \\
\hline For Females (Table 7, col. 4) & & & $0.19^{* * *}$ & 0.36 \\
\hline
\end{tabular}

As expected, the estimated levels of discount rates vary with the modeling assumptions. But, the estimated differences in discount rates are similar. We find that the relative ranking in discount rates across goods is stable and the three goods with higher discount rates appear

\footnotetext{
${ }^{41}$ We follow the procedures and data on calories and retention for Uganda from Appleton (2009) and we update prices with information from INFOTRADE (2010) for the relevant market in August 2010.

${ }^{42}$ Matooke is the principal staple in volume produced and consumed in the region (highest in the world), and an important part of the daily diet for local households.

${ }^{43}$ See Agras (2010) for a review of different explanations.
} 
in the first positions in all cases, even after taking good-specific confounding factors into account.

While there could be additional goods with larger discount rates than money, the point is that we can reject the hypothesis that time preferences are completely general. Furthermore, if we consider that matooke, sugar and meat are the goods with higher discount rates that are more relevant for our sample in terms of consumption, we can group them into a highdiscount group. This will allow us to test whether the share of expenditures on this group is decreasing or not with income, the key additional assumption that can explain a poverty trap when combined with self-control problems in the form of good-specific discounting.

\section{Application: Good-Specific Discounting and Poverty Traps}

\subsection{Self-Control Models: Good-Specific vs. Horizon-Specific Dis- counting}

The lack of self control can be understood as the inability of a person to follow through on a desired plan or action (Bernheim et al., 2011). As mentioned in the introduction, most of the attention in the literature modeling self-control problems has been focused on horizon-specific discounting models instead of good-specific discounting ${ }^{44}$

A simple example might help understand the differences between the horizon- and the good-specific discounting models. To show time-inconsistency with a quasi-hyperbolic model, we only need one good and three periods. The first period self maximizes $U\left(x_{1}\right)+\beta \delta U\left(x_{2}\right)+$ $\beta \delta^{2} U\left(x_{3}\right)$, while the second period self maximizes $U\left(x_{2}\right)+\beta \delta U\left(x_{3}\right)$, where $\delta$ is the discount factor (the inverse of the discount rate). The intertemporal marginal rate of substitution between period 3 and period 2 consumption has a weight of $\delta$ for period 1 self, but one of $\beta \delta$ for period 2 self. This generates a disagreement between the present and the future selves on the level of consumption over time 45 In the case of good-specific discount rates we can show time inconsistency with two goods and two periods. The first period self maximizes $U\left(x_{1}\right)+\delta_{x} U\left(x_{2}\right)+V\left(y_{1}\right)+\delta_{y} V\left(y_{2}\right)$, while the second period self maximizes $U\left(x_{2}\right)+V\left(y_{2}\right)$.

\footnotetext{
${ }^{44}$ An alternative literature models self-control problems without assuming time-inconsistent behaviors. See Lipman and Pesendorfer (2011) for a recent survey of these models where preferences are defined over menus instead of over consumption.

${ }^{45}$ Dual-selves economic models (Thaler and Shefrin, 1981 and Fudenberg and Levine, 2006) capture the idea that people are governed by multiple agents with different preferences. See also Milkman et al. (2008) for a psychological model of conflict between a "want" self focused on short-term pleasure and a "should" self representing long-term interests.
} 
Therefore, the marginal rate of substitution between goods $\mathrm{x}$ and $\mathrm{y}$ in period 2 has a weight of $\delta_{x} / \delta_{y}$ for period 1 self, but a weight of 1 for period 2 self. In this case, the disagreement between the present and the future self is on the composition of consumption. The timeconsistent case of no disagreement between the two selves is obtained when $\beta$ is one in the first case, and when $\delta_{x}=\delta_{y}$ in the second case.

\subsection{Extended Banerjee and Mullainathan Model}

Banerjee and Mullainathan (2010) present the first general model of self-control problems based on time inconsistency on the composition and not on the level of consumption. Different discount rates across goods generate a disagreement between the present and future selves on the composition of consumption. The possibility of self-control problems leading to a poverty trap rests on their assumption that expenditures in goods with higher discount rates increase less than proportionally with income.

In order to understand the assumptions required to predict a poverty trap, we can look at the Euler Equation derived from a general version of Banerjee and Mullainathan (2010), in the spirit of the extension presented in their appendix.

Consider an individual who lives two periods $t=1,2$ and can spend her income on two different components of consumption $x_{t}$ and $z_{t}$ (or indexes of spending on two groups of goods). The following utility function allows for different discount factors (the inverse of discount rates) for the two goods:

$$
U\left(x_{1}\right)+V\left(z_{1}\right)+\delta_{x} U\left(x_{2}\right)+\delta_{z} V\left(z_{2}\right)
$$

We can distinguish three relevant cases: 1) If $\delta_{x}=\delta_{z}$, this would be the utility function that a time-consistent individual with separable preferences maximizes; 2) if $\delta_{z}=0$, this becomes the utility function used by Banerjee and Mullainathan. Period 1 self does not value tomorrow's self spending on good $z$, which is seen as a good with no anticipatory utility, while $x$ is seen as a good that provides at least some anticipatory utility. And 3) If $\delta_{x}>\delta_{z}>0$, the model allows for the two selves giving some positive weight to the two components of consumption, but $x$ is weighted more heavily than $z$ by the forward-looking self.

We can choose units so that all prices are equal to 1, and proceed recursively to solve the optimization problem. For simplicity of exposition, following Banerjee and Mullainathan, let us assume that the individuals earn deterministic income $y_{1}$ in $t=1$. They can save $w_{1}=y_{1}-x_{1}-z_{1}$ and invest in an income generating function $f\left(w_{1}, \theta\right)$ with random shock $\theta$, where $f$ is increasing in $w_{1}$ (to allow for lending and borrowing with or without constraints 
at different rates), differentiable and concave in $w_{1}$. In $t=2$, the individual receives an uncertain income $y_{2}\left(\theta^{\prime}\right)$.

Period 2 self maximizes $U\left(x_{2}\right)+V\left(z_{2}\right)$ subject to the budget constraint $x_{2}+z_{2}=c_{2}$; the standard demands $x_{2}\left(c_{2}\right), z_{2}\left(c_{2}\right)$ are derived. Period 1 self is assumed to be sophisticated and takes these functions into account to maximize:

$U\left(x_{1}\right)+V\left(z_{1}\right)+\delta_{x} E_{\theta, \theta^{\prime}}\left\{U\left(x_{2}\left[c_{2}\left(\theta, \theta^{\prime}\right)\right]\right\}+\delta_{z} E_{\theta, \theta^{\prime}}\left\{V\left(z_{2}\left[c_{2}\left(\theta, \theta^{\prime}\right)\right]\right\}\right.\right.$, subject to $w_{1}=y_{1}-$ $x_{1}-z_{1}, c_{2}=f\left(w_{1}, \theta\right)+y_{2}\left(\theta^{\prime}\right)$, and non-negativity constraints. Assuming an interior solution exists, the Euler Equation for the problem is derived in (12):

$$
\frac{d U\left(x_{1}\right)}{d x_{1}}=\delta_{x} E_{\theta, \theta^{\prime}}\left\{\frac{d U\left(x_{2}\left(c_{2}\right)\right)}{d x_{2}} \frac{d f\left(w_{1}, \theta\right)}{d w_{1}}\right\}+\left(\delta_{x}-\delta_{z}\right) E_{\theta, \theta^{\prime}}\left\{\frac{d U\left(x_{2}\left(c_{2}\right)\right)}{d x_{2}} \frac{d f\left(w_{1}, \theta\right)}{d w_{1}} \frac{d z_{2}\left(c_{2}\right)}{d c_{2}}\right\}
$$

The implications of the three cases mentioned above are: 1) if $\delta_{x}=\delta_{z}$, the second term in (12) vanishes and yields the traditional Euler Equation for time-consistent consumer maximization problems. 2) if $\delta_{z}=0,(12)$ becomes

$$
\frac{d U\left(x_{1}\right)}{d x_{1}}=\delta_{x} E_{\theta, \theta^{\prime}}\left\{\frac{d U\left(x_{2}\left(c_{2}\left(\theta, \theta^{\prime}\right)\right)\right.}{d x_{2}} \frac{d f\left(w_{1}, \theta\right)}{d w_{1}}\left(1-\frac{d z_{2}\left(c_{2}\left(\theta, \theta^{\prime}\right)\right)}{d c_{2}}\right)\right\}
$$

The last term represents the part of the marginal unit moved to the future that is spent in goods that yield no utility for the present self (what Banerjee and Mullainathan call the "temptation tax"). Only the fraction $1-\frac{d z_{2}\left(c_{2}\right)}{d c_{2}}=\frac{d x_{2}\left(c_{2}\right)}{d c_{2}}$ is spent in what the forward-looking self wants; sophistication about future expenditures pushes the decision maker to spend more today than she would under perfect commitment. And 3) if $\delta_{x}>\delta_{z}>0$, the intuition is similar to the second case, we can see that there is a disincentive to save when the discount factors applied to the two goods are different. Lacking other commitment mechanisms, the individual will increase present consumption in order to limit the resources available for her future self.

When discount rates are different across goods, the shape of the last term plays an important role for the possibility of a poverty trap. It is precisely this term that allows selfcontrol problems to be related to economic circumstances. In particular, if $\frac{d z_{2}\left(c_{2}\right)}{d c_{2}}$ is constant, rich and poor are affected similarly by self-control problems: both groups face a disincentive to save. On the other hand, if $\frac{d z_{2}\left(c_{2}\right)}{d c_{2}}$ is decreasing in $c_{2}$, the richer are less affected by selfcontrol problems because they spend a smaller share of their income on high-discount goods and, therefore, they face a weaker disincentive to save. Only in this last case, the model predicts the possibility of a poverty trap ${ }^{46}$ Since we find higher discount rates for a group

\footnotetext{
${ }^{46}$ Technically, Banerjee and Mullainathan prove that if the derivative is constant, the maximization problem is strictly convex and the corresponding demand functions for $x_{t}$ and $z_{t}$ vary continuously with income. Whereas in the decreasing case the second order conditions of the problem would be violated for valid de-
} 
of goods, we can test the assumption required to predict a poverty trap by looking at the Engel Curves for the share of expenditures on these goods.

\subsection{Engel Curves}

The assumption that $\frac{d z_{2}\left(c_{2}\right)}{d c_{2}}$ is decreasing in $c_{2}$, can be evaluated in our case by looking at whether the fraction spent on matooke, sugar and meat (the three goods with higher discount rates identified as z goods) decreases with income (proxied by total expenditures 47 ). In order to do this, we use a module specially developed to capture expenditures in a typical month for the same goods for which we estimated discount rates in the first survey.

\subsubsection{Non-Parametric Estimation}

Our measure of total expenditures, calculated as the sum of reported expenditures in the 18 goods of the list (excluding money), has a high correlation (0.63) with the measure of total expenditures that includes every possible expenditure as reported in the background survey. To avoid the influence of outliers, we follow Banks et al. (1997) and trim any observation that lies outside three standard deviations of the mean for log expenditures and the good expenditure shares.

As a first piece of evidence, we present nonparametric kernel-weighted local linear regressions for the Engel Curves of the high-discount goods (matooke, sugar and meat) and for the low-discount rate good with largest share of expenditures in our sample (school supplies). Figure $1^{48}$ shows that the share of expenditures in sugar is decreasing in total expenditures, the share of meat increases initially and then decreases with total expenditures, and the share of matooke increases with total expenditures for a larger fraction of the distribution until it becomes approximately constant 49 In comparison, the share of expenditures on school supplies is almost constant for all the distribution of expenditures. This indicates that the required assumption to predict a poverty trap might be valid for sugar and meat, but not for matooke. The one for matooke is an interesting pattern, the main explanation in the literature would be that households switch to higher quality food items when total

mand functions and a local minimum can be found at a certain level of consumption, which implies that $c_{2}$ jumps discontinuously at a certain threshold of income.

${ }^{47}$ As Deaton and Zaidi (1999) point out, consumption is a more satisfactory measure than income for developing countries; we use expenditures data as our best approximation.

${ }^{48}$ We remove the tails in the graphs where estimation is less precise. The graphs were obtained using the lpoly command in Stata version 10.1, with degree 1, default Epanechnikov kernel and rule of thumb bandwidth. Results are robust to using different bandwidths.

${ }^{49}$ The turning point for the meat share Engel Curve is around 7.4 dollars or the $15^{\text {th }}$ percentile in the distribution of total expenditures, while for matooke it is only at around 20 dollars or the $45^{\text {th }}$ percentile. 
consumption increases, and that they consider matooke as a preferred food. This is a feasible explanation, since matooke is a relatively expensive source of calories 50

Nevertheless, when we divide goods into a high-discount (including sugar, meat and matooke) and a low-discount group (including the other 15 goods), we can see in Figure 2 that the Engel Curve for the share of the high-discount group presents a pattern in accordance to the assumption in the model, it decreases with income. ${ }^{51}$ It initially increases until around 9 dollars or the $20^{\text {th }}$ percentile in total expenditures, and then it decreases; with the inverse pattern for the low-discount group. Therefore, if we assumed that these three goods are the only ones, or at least the most relevant ones in terms of consumption, with higher discount rates, the assumption of the model would be satisfied.

\subsubsection{Parametric Estimation}

In order to control for observable factors, we calculate elasticities following Banks et al. (1997). We first estimate quadratic ${ }^{52}$ OLS equations for the share of each good or group of goods on log expenditures, controlling for observable characteristics (size of the household, fraction of children over total members in the household, age, dummies for gender, literacy, ability scores, and location 53 . Elasticities are then calculated using the estimated coefficients for each individual, and a weighted average is constructed with weights being equal to the individual's share of total sample expenditure for the good.

The elasticities presented in Table 9 validate the intuition from the graphs. We can see that average weighted elasticities for sugar and meat are statistically significantly lower than one, while for matooke the elasticity is larger than one. Similarly, for school supplies, the lowdiscount good with larger expenditure share, the average elasticity is larger than 1 . When we divide goods into two groups, we see that the average weighted elasticity for the highdiscount group, which represents $47 \%$ of expenditures, is 0.91 and statistically significantly lower than 1. Again, this provides evidence for the key assumption in the model.

\footnotetext{
${ }^{50}$ See also Jensen and Miller $\sqrt{2010)}$ for a related explanation in terms of Engel Curves for calories shares. Kedir and Girma (2007) find as well a turning point for food at high levels of expenditures for Ethiopia.

${ }^{51} \mathrm{As}$ Banerjee and Mullainathan (2010) remark, the assumption does not necessarily hold for people who are at the margin of starvation, for whom the first units of nutritious goods might be more valuable than any other good. This can explain the initial increase in the Engel Curve for the high-discounting group in Figure 2.

${ }^{52}$ As Banks et al. (1997) explain, parsimony and the properties derived from utility theory restrict the non-linear terms in Engel Curves to being quadratic in log income.

${ }^{53}$ The location dummies are used as controls for variation in relative prices, which are relatively homogenous in our area of study. As Attanasio et al. (2009) point out, if relative prices diverged across villages they would enter non-linearly in the regressions.
} 


\subsubsection{Caveats}

The results in this section are subject to some caveats. Firstly, we have detected only three goods with significantly higher discount rates, but it could be the case that there are other goods that also exhibit high discount rates. If some of these goods behave like matooke in our sample, we could see expenditures in the high-discount group actually increasing with income. Secondly, it is possible that for a population with a greater variation in income, consumption of goods like matooke would reach satiation at even lower percentiles of the distribution, and the assumption of decreasing expenditures might become more feasible. Thirdly, we are using data on expenditures, data on consumption might lead to different results. In particular, there is an important trade-off for households in our sample about consuming the matooke they produce or selling it at higher prices, we are not able to capture this trade-off with our data.

Finally, it is important to control for endogeneity and non-classical measurement error ${ }^{54}$ in the estimation of the Engel Curves. As Attanasio et al. (2009) point out, total expenditures might be correlated with the residuals of the demand system and different taste shifters for different goods might generate bias in opposite directions. However, the typical instrumental variables used in the literature for developed countries are wages or labor income, which are not valid instruments under non-separability between consumption and leisure choices, a typical finding in developing countries. Attanasio et al. (2009) use expected income range as instrumental variable in one of the few papers using instrumental variables to estimate Engel Curves for a developing country. After instrumenting for total expenditure, they find that food is a necessity for almost every household in their sample; while their OLS estimates indicated that food only becomes a necessity after the $10^{\text {th }}$ or $20^{\text {th }}$ percentile in total expenditures, depending on the specification.

In preliminary analysis, we use the estimator proposed by Chernozhukov et al. (2009) to control for endogeneity following a control function approach. We use as instruments three dummy variables measuring expected income trends following a similar logic to the one by Attanasio et al. (2009). These variables are self-reported indicators on whether the respondent expects her income in two months to be higher, lower or the same as expected income in one month. They are jointly significant in the first stage for total expenditures even after including covariates. When we replicate the procedures to calculate elasticities in Table 9, we find for the high-discount group an average weighted budget elasticity of 0.66 with standard error of 0.01 obtained with 100 bootstrap replications (results available upon request). This value is lower than the OLS one, and statistically significantly below

\footnotetext{
${ }^{54}$ See Lewbel (1996) and Kedir and Girma $(2007)$ for the implications on non-classical measurement error in this context.
} 
1. Although this preliminary analysis raises concerns about the importance of controlling appropriately for endogeneity, it validates our previous conclusions.

\section{Concluding Remarks}

Most of the literature providing empirical evidence to model self-control problems has focused on showing that discount rates might decrease with the time horizon. However, we can also obtain time-inconsistent behaviors if we allow for discount rates being different across goods. This paper provides evidence rejecting the hypothesis that the same discount rate is applied to the utility of all possible sources of consumption, implying that self-control problems could be modeled using good-specific discount rates.

We find significantly higher discount rates for three goods than for money and a list of other goods available in the area under study. Furthermore, we show that although the estimated levels of discount rates vary when we relax the main modeling assumptions needed to identify discount rates, the relative ranking across goods is stable. The differences we find in discount rates across goods are not only robust to controlling for the main confounding factors mentioned in the literature (such as the use of hypothetical instead of real choices, the assumption of zero background consumption and the curvature of the utility function), but also for good-specific factors (including resale opportunities, expected prices and storage capacity).

We estimate discount rates for a sample of poor rural households with characteristics that are also observed in other countries of Eastern Africa. While our list of goods is specific to the area under study in Central Uganda, our procedures can be replicated in other contexts. Our goal is to present robust evidence for good-specific discounting in at least one context.

In addition, this context is particularly relevant for the application of our results. This paper is the first to provide empirical evidence for the assumptions required to predict a lowasset poverty trap generated by self-control problems in the form of good-specific discounting. By estimating Engel Curves, we show that the share of expenditures on goods with higher discount rates is decreasing with income. Although several extensions should be considered in the estimation of the Engel Curves (such as the use of consumption data and improved methods to control for endogeneity), our results imply that the poor might face a stronger disincentive to save. They might increase present consumption in order to prevent their future selves from spending resources in goods with high discount rates.

An implication of this finding is a general demand for commitment devices as a direct consequence of self-control problems. Nevertheless, the optimal type of commitment device that would be required to face self-control problems generated by good-specific discounting 
might be different that the general device restricting cash availability that has been studied in the literature. 55 An important topic for future research is to understand what specific commitment devices are best fitted to face the disagreement in the composition of consumption between the present and the future self.

The existence of a poverty trap would indicate that one-time interventions helping the poor start saving can have high impact. In ongoing work, we are conducting a field experiment in which we encourage a random sample of the unbanked individuals studied in this paper to open a savings account (by covering account opening fees). This design will enable us to test whether a simple bank account can offer enough of a commitment mechanism to reduce future consumption on high-discount goods and thereby encourage savings among the poor.

The finding that the poor spend large shares of their income on relatively expensive sources of calories is not unique to our paper and it has been mentioned as one of the factors for their low savings. Banerjee and Duflo (2007) show that the poor around the world spend up to $7 \%$ of their income on "expensive calories", such as sugar, while neglecting cheaper nutritious alternatives. Subramanian and Deaton (1996) note that the poorest decile of rural households in Maharashtra spends $12.2 \%$ of their total expenditures on sugar, oils and fats. In our case, for rural households in Uganda, we find that the three goods with significantly higher discount rates are sugar, matooke and beef; which also represent expensive sources of calories and capture a large share of total expenditures (a 13\% of total expenditures estimated in the baseline survey). In this paper, we present indirect evidence for the conditions that generate a higher disincentive to save for the poor due to self-control problems in the form of good-specific discount rates. A topic for future research is to design direct tests to estimate the relationship between differences in discount rates across goods, expenditures in expensive sources of calories and low savings.

Finally, another topic for future research is related to the effect of taxes on goods with high discount rates. In a model of two goods (consumption and leisure) and infinite periods, Futagami and Hori (2010) show that the optimal consumption tax is not zero. However, in the context of the model by Banerjee and Mullainathan (2010), with $\mathrm{n}$ goods and a finite number of periods, a tax on the high-discount goods might reduce their consumption, but it could also increase the share of expenditures on those goods, making the self-control problem even more relevant. The result will depend on the price elasticities of demand. Studies designed to estimate these elasticities and relate them to discount rates can help us understand the impact of taxation and food subsidies in this context.

\footnotetext{
${ }^{55}$ An example could be the product explored by Gine et al. (2010) that reduces expenditures in tobacco, although the goal of that product was to help people quit smoking.
} 


\section{References}

Agras, W. (2010). The Oxford Handbook of Eating Disorders. Oxford Library of Psychology. Oxford University Press.

Andersen, S., G. W. Harrison, M. I. Lau, and E. E. Rutstrom (2008). Eliciting Risk and Time Preferences. Econometrica 76(3), 583-618.

Andersen, S., G. W. Harrison, M. I. Lau, and E. E. Rutstrom (2011a). Discounting Behavior: A Reconsideration. Working Paper 2011-03, Center for Economic Analysis of Risk, Robinson College of Business, Georgia State University.

Andersen, S., G. W. Harrison, M. I. Lau, and E. E. Rutstrom (2011b). Discounting Behavior and the Magnitude Effect. Working Paper 2011-01, Center for Economic Analysis of Risk, Robinson College of Business, Georgia State University.

Anderson, S. and J. M. Baland (2002). The Economics of Roscas and Intrahousehold Resource Allocation. The Quarterly Journal of Economics 117(3), 963-995.

Andreoni, J., M. Kuhn, and C. Sprenger (2012). Measuring Time Preferences with Simple Tasks: the Value of Multinomial Choice. UCSD.

Andreoni, J. and C. Sprenger (2010). Estimating Time Preferences from Convex Budgets. Forthcoming, American Economic Review.

Appleton, S. (2009). How Sensitive Should Poverty Lines Be to Time and Space? An Application to Uganda. Nottingham University, School of Economics.

Ashraf, N. (2009). Spousal Control and Intra-household Decision Making: An Experimental Study in The Philippines. American Economic Review 99(4), 1245-77.

Ashraf, N., D. Karlan, and W. Yin (2006). Tying Odysseus to the Mast: Evidence from a Commitment Savings Product in The Philippines. Quarterly Journal of Economics 121(2), 635-672.

Attanasio, O., E. Battistin, and A. Mesnard (2009). Food and Cash Transfers:Evidence from Colombia. CEPR Discussion Papers 7326.

Azariadis, C. and J. Stachurski (2005). Poverty Traps. Volume 1 of Handbook of Economic Growth, Chapter 5. Editors Philippe Aghion and Steven Durlauf. Elsevier.

Banerjee, A. and S. Mullainathan (2010). The Shape of Temptation: Implications for the Economic Lives of the Poor. National Bureau of Economic Research, NBER Working Papers 15973. 
Banerjee, A. V. and E. Duflo (2007). The Economic Lives of the Poor. Journal of Economic Perspectives 21(1), 141-167.

Banks, J., R. Blundell, and A. Lewbel (1997). Quadratic Engel Curves and Consumer Demand. The Review of Economics and Statistics 79(4), 527-539.

Bauer, M. and J. Chytilova (2009). The Impact of Education on the Subjective Discount Rate in Ugandan Villages. Institute for the Study of Labor (IZA), Discussion Papers 4057.

Bauer, M., J. Chytilova, and J. Morduch (2010). Behavioral Foundations of Microcredit: Experimental and Survey Evidence from Rural India. Institute for the Study of Labor (IZA), Discussion Papers 4901.

Benhabib, J., A. Bisin, and A. Schotter (2010). Present-Bias, Quasi-Hyperbolic Discounting, and Fixed Costs. Games and Economic Behavior 69(2), 205-223.

Bernheim, D., D. Ray, and S. Yeltekin (1999). Self-control, Saving and the Low Asset trap. Mimeo, Standford University.

Bernheim, D., D. Ray, and S. Yeltekin (2011). Poverty and Self-control. Technical Report.

Bickel, W., R. Landes, D. Christensen, L. Jackson, B. Jones, Z. Kurth-Nelson, and A. Redish (2011). Single- and Cross-commodity Discounting Among Cocaine Addicts: The Commodity and its Temporal Location Determine Discounting Rate. Psychopharmacology, 1-11.

Brune, L., X. Gine, J. Goldberg, and D. Yang (2011). Commitments to Save: a Field Experiment in Rural Malawi. Mimeo, University of Michigan.

Bryan, G., D. S. Karlan, and S. Nelson (2010). Commitment Devices. Annual Review of Economics 2, 671-698.

Chabris, C., D. Laibson, and J. Schuldt (2008). Intertemporal Choice. In Durlauf, S. and Blume, L. (Eds.). The New Palgrave Dictionary of Economics (2nd ed.). London: Palgrave: Macmillan.

Chapman, G. (1996). Temporal Discounting and Utility for Health and Money. Journal of Experimental Psychology: Learning, Memory and Cognition 22, 771-791.

Charlton, S. R. and E. Fantino (2008). Commodity Specific Rates of Temporal Discounting: Does Metabolic Function Underlie Differences in Rates of Discounting? Behavioural Processes 77(3), $334-342$.

Chernozhukov, V., I. Fernandez-Val, and A. E. Kowalski (2009). Censored Quantile Instrumental Variable Estimation via Control Functions. Boston University - Department of 
Economics - Working Papers Series 2009-12.

Coller, M., G. W. Harrison, and E. E. Rutstrom (2011). Latent Process Heterogeneity in Discounting Behavior. Forthcoming Oxford Economic Papers.

Coller, M. and M. Williams (1999). Eliciting Individual Discount Rates. Experimental Economics 2(2), 107-127.

Collins, D., J. Morduch, S. Rutherford, and O. Ruthven (2009). Portfolios of the Poor: How the World's Poor Live on 2 dollars a Day. Princeton University Press. Princeton University Press.

Deaton, A. and S. Zaidi (1999). Guidelines for Constructing Consumption Aggregates for Welfare Analysis. Princeton, Woodrow Wilson School - Dev. Studies, Paper 192.

DellaVigna, S. (2009). Psychology and Economics: Evidence from the Field. Journal of Economic Literature 47(2), 315-72.

Duflo, E., M. Kremer, and J. Robinson (2010). Nudging Farmers to Use Fertilizer: Theory and Experimental Evidence from Kenya. Forthcoming, American Economic Review.

Dupas, P. and J. Robinson (2009). Savings Constraints and Microenterprise Development: Evidence from a Field Experiment in Kenya. NBER Working Papers 14693.

Dupas, P. and J. Robinson (2011). Why Don't the Poor Save More? Evidence from Health Savings Experiments. NBER Working Papers Series 17255.

Dupas, P. and J. Robinson (2012). Savings Constraints and Microenterprise Development: Evidence from a Field Experiment in Kenya. AEJ: Applied Economics. Forthcoming.

Einav, L., A. Finkelstein, I. Pascu, and M. R. Cullen (2010). How General Are Risk Preferences? Choices Under Uncertainty in Different Domains. NBER Working Papers 15686.

Estle, S. J., L. Green, J. Myerson, and D. D. Holt (2007). Discounting of Monetary and Directly Consumable Rewards. Psychological Science 18, 58-63.

Fafchamps, M., D. McKenzie, S. Quinn, and C. Woodruff (2011). When is Capital Enough to Get Female Enterprises Growing? Evidence From a Randomized Experiment in Ghana. The World Bank, Policy Research Working Paper Series 5706.

Frederick, S., G. Loewenstein, and T. O'Donoghue (2002). Time Discounting and Time Preference: A Critical Review. Journal of Economic Literature 40 (2), 351-401.

Fudenberg, D. and D. K. Levine (2006). A Dual-Self Model of Impulse Control. American Economic Review 96(5), 1449-1476. 
Futagami, K. and T. Hori (2010). A Non-Unitary Discount Rate Model. Osaka University, Graduate School of Economics and Osaka School of International Public Policy (OSIPP), Discussion Papers in Economics and Business 10-26.

Gine, X., D. Karlan, and J. Zinman (2010). Put Your Money Where Your Butt Is: A Commitment Contract for Smoking Cessation. American Economic Journal: Applied Economics 2(4), 213-35.

Green, L. and J. Myerson (2004). A Discounting Framework for Choice With Delayed and Probabilistic Rewards. Psychological Bulletin 130(5), 769 - 792.

Harrison, G. W. and E. E. Rutstrom (2008). Risk Aversion in the Laboratory. Emerald Group Publishing Limited. In James C. Cox, Glenn W. Harrison (ed.) Risk Aversion in Experiments (Research in Experimental Economics, Volume 12) pp. 41-196.

Holden, S. T., B. Shiferaw, and M. Wik (1998). Poverty, Market Imperfections and Time Preferences: Of Relevance for Environmental Policy? Environment and Development Economics 3(01), 105-130.

INFOTRADE (2010). Market Report August 23, 2010. Volume 2, number 10.

Jakiela, P. and O. Ozier (2011). Does Africa Need a Rotten Kin Theorem? Experimental Evidence from Village Economies. Mimeo, University of Washington at St Louis.

Jensen, R. T. and N. H. Miller (2010). A Revealed Preference Approach to Measuring Hunger and Undernutrition. NBER Working Paper Series 16555.

Kedir, A. and S. Girma (2007). Quadratic Engel Curves with Measurement Error: Evidence from a Budget Survey. Oxford Bulletin of Economics and Statistics 69(1), 123138.

Klemick, H. and M. Yesuf (2008). Do Discount Rates Change over Time? Experimental Evidence from Ethiopia. Discussion Paper Series EfD DP 08-06, Environment for Development.

Laibson, D. (1997). Golden Eggs and Hyperbolic Discounting. The Quarterly Journal of Economics 112(2), 443-77.

Laury, S. K., M. M. McInnes, J. T. Swarthout, and E. V. Nessen (2011). Avoiding the Curves: Direct Elicitation of Time Preferences. Experimental Economics Center, Andrew Young School of Policy Studies, Georgia State University. Working Paper Series 2011-01.

Lewbel, A. (1996). Demand Estimation with Expenditure Measurement Errors on the Left and Right Hand Side. The Review of Economics and Statistics 78(4), 718-25. 
Lipman, B. L. and W. Pesendorfer (2011). Temptation. Mimeo.

McClure, S. M., K. Ericson, D. I. Laibson, G. Loewenstein, and J. D. Cohen (2007). Time discounting for primary rewards. The Journal of Neuroscience 27(21), 5796-5804.

McClure, S. M., D. I. Laibson, G. Loewenstein, and J. D. Cohen (2004). Separate Neural Systems Value Immediate and Delayed Monetary Rewards. Science 306(5695), 503507.

Milkman, K. L., T. Rogers, and M. H. Bazerman (2008). Harnessing Our Inner Angels and Demons: What We Have Learned About Want/Should Conflicts and How That Knowledge Can Help Us Reduce Short-Sighted Decision Making. Perspectives on Psychological Science 3(4), 324-338.

Moav, O. and Z. Neeman (2008). Conspicuous Consumption, Human Capital and Poverty. CEPR Discussion Papers 6864.

Noor, J. (2009). Hyperbolic Discounting and the Standard Model: Eliciting Discount Functions. Journal of Economic Theory 144(5), 2077-2083.

O'Donoghue, T. and M. Rabin (1999, March). Doing it now or later. American Economic Review 89(1), 103-124.

Odum, A., A. Baumann, and D. Rimington (2006). Discounting of Delayed Hypothetical Money and Food: Effects of Amount. Behavioural Processes 73, 278 - 284.

Odum, A. and C. Rainaud (2003). Discounting of Delayed Hypothetical Money, Alcohol, and Food. Behavioural Processes 64 (3), $305-313$.

Phelps, E. S. and R. A. Pollak (1968). On Second-Best National Saving and GameEquilibrium Growth. The Review of Economic Studies 35 (2), 185-199.

Reuben, E., P. Sapienza, and L. Zingales (2010). Time Discounting for Primary and Monetary Rewards. Economics Letters 106 (2), 125-127.

Samuelson, P. (1937). A Note on Measurement of Utility. Review of Economic Studies 4(2), $155-161$.

Schaner, S. (2011). Intrahousehold Preference Heterogeneity, Commitment, and Strategic Savings: Theory and Evidence from Kenya. Mimeo, MIT.

Shapiro, J. (2010). Discounting for You, Me and We: Time Preference in Groups and Pairs. Mimeo.

Soman, D., G. Ainslie, S. Frederick, X. Li, J. Lynch, P. Moreau, A. Mitchell, D. Read, A. Sawyer, Y. Trope, K. Wertenbroch, and G. Zauberman (2005). The Psychology of 
Intertemporal Discounting: Why are Distant Events Valued Differently from Proximal Ones? Marketing Letters 16(3), 347-360.

Strotz, R. H. (1956). Myopia and Inconsistency in Dynamic Utility Maximization. Review of Economic Studies 23, 1955-1956(3), 165-180.

Subramanian, S. and A. Deaton (1996). The Demand for Food and Calories. Journal of Political Economy 104(1), 133-162.

Thaler, R. H. and H. M. Shefrin (1981). An Economic Theory of Self-Control. Journal of Political Economy 89(2), 392-406.

Tsukayama, E. and A. Duckworth (2010). Domain-Specific Temporal Discounting and Temptation. Judgment and Decision Making 5(2), 72-82.

Wilcox, N. (2011). "Stochastically More Risk Averse:" A Contextual Theory of Stochastic Discrete Choice Under Risk. Journal of Econometrics 162(1), 89-104. 
Table 1. Basic Socio-Economics Characteristcs. Samples for Survey 1 and 2

\begin{tabular}{lcccc|cccc}
\hline \multicolumn{1}{c}{ Variable } & \multicolumn{4}{c}{ Full Sample } & \multicolumn{4}{c}{ Survey 2 Subsample } \\
& Mean & Median & Sd. & Obs. & Mean & Median & Sd. & Obs. \\
\hline Female & 0.71 & 1.00 & 0.45 & 2,442 & 0.70 & 1.00 & 0.46 & 449 \\
Age & 36.15 & 34.00 & 11.83 & 2,442 & 37.04 & 35.00 & 12.06 & 449 \\
Married & 0.73 & 1.00 & 0.44 & 2,441 & 0.76 & 1.00 & 0.43 & 449 \\
Household Size & 6.82 & 6.00 & 3.29 & 2,442 & 6.94 & 6.00 & 3.25 & 449 \\
Education (years) & 5.72 & 6.00 & 3.03 & 2,440 & 5.54 & 6.00 & 3.01 & 449 \\
Literate (in Luganda) & 0.77 & 1.00 & 0.42 & 2,437 & 0.75 & 1.00 & 0.43 & 449 \\
Land (acres) & 1.56 & 1.00 & 2.18 & 2,390 & 1.53 & 1.00 & 1.90 & 441 \\
Farms at least 1 crop & 0.85 & 1.00 & 0.36 & 2,442 & 0.90 & 1.00 & 0.31 & 440 \\
Sells at least 1 crop & 0.65 & 1.00 & 0.48 & 2,442 & 0.64 & 1.00 & 0.48 & 449 \\
Value Crops Sold Last Harvest (dollars) & 51.26 & 10.37 & 104.19 & 2,372 & 58.61 & 8.73 & 132.51 & 440 \\
Used Fertilizer Last Harvest & 0.10 & 0.00 & 0.30 & 2,178 & 0.09 & 0.00 & 0.29 & 411 \\
Digits memory test (\% correct) & 44.88 & 43.75 & 14.39 & 2,441 & 45.16 & 43.75 & 14.94 & 449 \\
Raven's matrix cognitive test (\% correct) & 48.74 & 50.00 & 23.79 & 2,431 & 46.94 & 41.67 & 23.48 & 447 \\
\hline
\end{tabular}

Notes: Summary statistics for the 2,442 individuals included in the first survey are presented in the left panel, while those resticting the sample to the 449 individuals interviewed again in the second survey are presented in the right panel. 
Table 2. Discount Rates Basic Procedure

\begin{tabular}{lccccc}
\hline \hline \multicolumn{1}{c}{ Discount Rate } & Mean & $\begin{array}{c}\text { 95\% } \\
\text { Lower } \\
\text { Bound }\end{array}$ & $\begin{array}{c}\text { 95\% } \\
\text { Upper } \\
\text { Bound }\end{array}$ & Median & Obs. \\
\hline Meat & 1.100 & 1.060 & 1.140 & $\mathbf{0 . 7 5 0}$ & 2,434 \\
Sugar & 1.020 & 0.990 & 1.060 & $\mathbf{0 . 7 5 0}$ & 2,441 \\
Matooke & 1.000 & 0.970 & 1.040 & $\mathbf{0 . 7 5 0}$ & 2,438 \\
Average Over All Goods+ & 0.810 & 0.780 & 0.840 & $\mathbf{0 . 5 3 0}$ & 2,442 \\
Money & 0.900 & 0.860 & 0.940 & 0.250 & 2,440 \\
Beans & 0.880 & 0.850 & 0.920 & 0.250 & 2,438 \\
Meals Outside & 0.810 & 0.780 & 0.850 & 0.250 & 2,436 \\
Lotion & 0.810 & 0.780 & 0.850 & 0.250 & 2,419 \\
Perfume & 0.770 & 0.740 & 0.810 & 0.250 & 2,411 \\
School Supplies & 0.760 & 0.720 & 0.790 & 0.250 & 2,438 \\
Snacks & 0.740 & 0.710 & 0.780 & 0.250 & 2,440 \\
Airtime & 0.740 & 0.700 & 0.770 & 0.250 & 2,434 \\
Clothes & 0.740 & 0.710 & 0.770 & 0.250 & 2,433 \\
Shoes & 0.740 & 0.710 & 0.770 & 0.250 & 2,440 \\
Entertainment++ & 0.730 & 0.700 & 0.770 & 0.250 & 2,332 \\
Soda & 0.720 & 0.690 & 0.750 & 0.250 & 2,440 \\
Saloon+++ & 0.700 & 0.670 & 0.730 & 0.250 & 2,430 \\
Salt & 0.660 & 0.630 & 0.690 & 0.250 & 2,436 \\
\hline Notes: + Average over the discount rates for all goods in the list. ++ Entrance tickets to \\
standard local shows. +++ Voucher to use at hairdresser/barber. & & \\
\hline & & & & &
\end{tabular}


Table 3. Pooled Regression

\begin{tabular}{|c|c|c|c|}
\hline \multirow[b]{2}{*}{$\begin{array}{l}\text { Dependent Variable: person- } \\
\text { good specific discount rate }\end{array}$} & \multicolumn{2}{|c|}{ Pooled Regression+ } & \multirow{2}{*}{$\begin{array}{c}\begin{array}{c}\text { Interval } \\
\text { Regression++ }\end{array} \\
\text { Equal Value } \\
\text { (3) }\end{array}$} \\
\hline & $\begin{array}{l}\text { Equal Value } \\
\text { (1) }\end{array}$ & $\begin{array}{l}\text { All Questions } \\
\text { (2) }\end{array}$ & \\
\hline Matooke & $\begin{array}{c}0.104^{\star \star \star} \\
(0.02)\end{array}$ & $\begin{array}{c}0.047^{\star \star \star} \\
(0.01)\end{array}$ & 0.101 \\
\hline Sugar & $\begin{array}{c}0.125^{\star * \star} \\
(0.02)\end{array}$ & $\begin{array}{c}0.049 * * * \\
(0.01)\end{array}$ & 0.130 \\
\hline Meat & $\begin{array}{c}0.199 * \star \star \\
(0.02)\end{array}$ & $\begin{array}{c}0.066^{\star \star \star} \\
(0.01)\end{array}$ & 0.216 \\
\hline Beans & -0.014 & $-0.040^{* * *}$ & -0.017 \\
\hline Soda & $-0.178^{\star \star \star}$ & $-0.079^{* * *}$ & -0.188 \\
\hline Salt & $-0.239^{\star * *}$ & $-0.124^{* * *}$ & -0.252 \\
\hline Meals Outside & $-0.087^{\star * *}$ & -0.011 & -0.106 \\
\hline Snacks & $-0.154^{\star \star *}$ & -0.003 & -0.173 \\
\hline Clothes & $-0.159^{* * *}$ & $-0.141^{* * *}$ & -0.163 \\
\hline Lotion & $-0.081^{\star * \star}$ & $-0.094^{* * *}$ & -0.095 \\
\hline Shoes & $-0.162^{* \star *}$ & $-0.139^{* * *}$ & -0.166 \\
\hline Perfume & $-0.119^{\star \star \star}$ & $-0.121^{\star \star \star}$ & -0.134 \\
\hline Entertainment & $-0.165^{\star \star *}$ & $-0.116^{* * *}$ & -0.182 \\
\hline Saloon & $-0.200^{\star \star \star}$ & $-0.135^{\star \star \star}$ & -0.212 \\
\hline School Supplies & $-0.141^{* * *}$ & $-0.115^{* * *}$ & -0.150 \\
\hline Airtime & $-0.161^{\star \star *}$ & $-0.105^{\star \star *}$ & -0.170 \\
\hline Question: Small Quantities & & $0.055^{\star * *}$ & \\
\hline Question: Equal Value & & $0.091^{\star \star *}$ & \\
\hline Constant & 0.896 & 0.765 & 0.889 \\
\hline Households & 2,442 & 2,442 & 2,442 \\
\hline Observations & 43,170 & 124,646 & \\
\hline \multicolumn{4}{|c|}{$\begin{array}{l}\text { Notes: }{ }^{* * *},{ }^{* *},{ }^{*}: \text { significant at } 1,5 \text { and } 10 \% \text { level, respectively. + Money is the omitted good. } \\
\text { Columns } 1-2 \text { show the results from the regression of the discount rate, estimated at the } \\
\text { question level, on goods and magnitudes dummies, the constant captures the average } \\
\text { discount rate for money. Column } 1 \text { is restricted to equal-value choices. ++ Column } 3 \text { shows } \\
\text { the results of interval regressions for each good, the differences in predicted discount rates } \\
\text { between each good and money are presented; the constant captures the predicted discount } \\
\text { rate for money. Standard errors clustered at the individual level in parenthesis, available upon } \\
\text { request where omitted. }\end{array}$} \\
\hline
\end{tabular}


Table 4. Joint Estimation. Equal-Value Questions

\begin{tabular}{|c|c|c|c|c|c|}
\hline $\begin{array}{l}\text { Individual } \\
\text { Estimation for } \\
\text { each good }\end{array}$ & $\begin{array}{c}\text { Coefficient } \\
\text { (1) }\end{array}$ & $\begin{array}{l}95 \% \\
\text { Lower } \\
\text { Bound } \\
(2)\end{array}$ & $\begin{array}{c}95 \% \\
\text { Upper } \\
\text { Bound } \\
\text { (3) }\end{array}$ & $\begin{array}{c}\text { Predicted } \\
\text { Value for } \\
\text { Females }^{*} \\
(4)\end{array}$ & $\begin{array}{l}\text { Obs. } \\
(5)\end{array}$ \\
\hline Meat & 0.589 & 0.55 & 0.63 & 0.50 & 41,456 \\
\hline Matooke & 0.560 & 0.52 & 0.60 & 0.48 & 41,480 \\
\hline Sugar & 0.544 & 0.50 & 0.58 & 0.46 & 41,498 \\
\hline Beans & 0.416 & 0.38 & 0.45 & 0.33 & 41,480 \\
\hline Money & 0.362 & 0.32 & 0.40 & 0.29 & 41,492 \\
\hline Lotion & 0.349 & 0.31 & 0.38 & 0.28 & 41,366 \\
\hline Perfume & 0.295 & 0.26 & 0.33 & 0.25 & 41,318 \\
\hline ALL GOODS** & 0.257 & 0.23 & 0.29 & & 739,958 \\
\hline Clothes & 0.217 & 0.18 & 0.26 & 0.18 & 41,450 \\
\hline Shoes & 0.212 & 0.17 & 0.25 & 0.18 & 41,492 \\
\hline School Supplies & 0.192 & 0.15 & 0.23 & 0.15 & 41,480 \\
\hline Meals Outside & 0.171 & 0.13 & 0.22 & 0.12 & 41,468 \\
\hline Soda & 0.153 & 0.11 & 0.20 & 0.11 & 41,492 \\
\hline Airtime & 0.152 & 0.11 & 0.19 & 0.09 & 41,456 \\
\hline Saloon & 0.099 & 0.06 & 0.14 & 0.09 & 41,432 \\
\hline Entertainment & 0.058 & 0.01 & 0.11 & 0.06 & 40,844 \\
\hline Snacks & 0.049 & 0.00 & 0.10 & 0.07 & 41,492 \\
\hline Households & & & & & 2,442 \\
\hline \multicolumn{6}{|c|}{$\begin{array}{l}\text { Notes: Column 1-3 present MLE estimates for each good, the upper and lower bounds } \\
\text { were calculated with standard errors clustered at the individual level. The risk aversion } \\
\text { parameter and structural errors terms for risk and time preferences were also re-estimated } \\
\text { in each case. *Column } 4 \text { presents the predicted discount rate for females based on the } \\
\text { coefficient obtained when we allow both the discount rate and risk aversion parameter to } \\
\text { depend on observable characteristics, dummies for being female, married, low ability } \\
\text { scores and literate were also included. }{ }^{*} \text { Presents results from a similar pooling choices } \\
\text { for all goods. }\end{array}$} \\
\hline
\end{tabular}


Table 5. Basic Procedure. Real vs. Hypothetical Rewards (equal-value questions)

Survey 1: Hypothetical Rewards

Survey 2: Real Rewards

\begin{tabular}{lcccc|ccccc}
\hline \multicolumn{1}{c}{ Good } & Mean & $\begin{array}{c}\mathbf{9 5 \%} \\
\text { Lower } \\
\text { Bound }\end{array}$ & $\begin{array}{c}\mathbf{9 5 \%} \\
\text { Upper } \\
\text { Bound }\end{array}$ & Median & Mean & $\begin{array}{c}\mathbf{9 5 \%} \\
\text { Lower } \\
\text { Bound }\end{array}$ & $\begin{array}{c}\mathbf{9 5 \%} \\
\text { Upper } \\
\text { Bound }\end{array}$ & Median & Obs. \\
\hline Sugar & 1.09 & 1.00 & 1.18 & $\mathbf{0 . 7 5}$ & 1.11 & 1.00 & 1.21 & $\mathbf{0 . 7 5}$ & 449 \\
Beef & 1.11 & 1.02 & 1.20 & $\mathbf{0 . 7 5}$ & 1.07 & 0.97 & 1.18 & $\mathbf{0 . 7 5}$ & 449 \\
Matooke & 1.02 & 0.94 & 1.11 & $\mathbf{0 . 7 5}$ & 1.04 & 0.94 & 1.15 & $\mathbf{0 . 7 5}$ & 449 \\
Cash & 0.86 & 0.78 & 0.94 & 0.25 & 0.88 & 0.79 & 0.98 & 0.25 & 449 \\
Airtime & 0.77 & 0.69 & 0.85 & 0.25 & 0.81 & 0.72 & 0.91 & 0.25 & 449 \\
School Supplies & 0.73 & 0.65 & 0.80 & 0.25 & 0.86 & 0.72 & 0.95 & 0.25 & 449 \\
\hline
\end{tabular}

Notes: Summary statistics for the discount rates calculated using hypothetical rewards are presented in the left panel (only for those who were also surveyed in the second survey), while those calculated with real rewards are presented in the right panel. 
Table 6. Fixed Effects Regression. Real Rewards

\begin{tabular}{|c|c|c|c|c|c|}
\hline \multirow{2}{*}{$\begin{array}{l}\text { Dependent Variable: person- } \\
\text { good specific discount rate }\end{array}$} & \multirow{2}{*}{$\begin{array}{l}\text { Small Quantities } \\
\qquad(1)\end{array}$} & \multicolumn{4}{|c|}{ All Questions } \\
\hline & & $(2)$ & (3) & (4) & (5) \\
\hline \multirow[t]{2}{*}{ Matooke } & $0.157^{\star \star \star}$ & $0.172^{\star \star \star}$ & $0.170^{\star \star \star}$ & $0.136^{\star \star \star}$ & $0.142^{\star \star \star}$ \\
\hline & $(0.04)$ & $(0.04)$ & $(0.04)$ & $(0.04)$ & $(0.04)$ \\
\hline \multirow[t]{2}{*}{ Sugar } & $0.224^{\star \star \star}$ & $0.262^{\star \star \star}$ & $0.266^{\star \star \star}$ & $0.239^{\star \star \star}$ & $0.256^{\star \star \star}$ \\
\hline & $(0.04)$ & $(0.04)$ & $(0.04)$ & $(0.04)$ & $(0.04)$ \\
\hline \multirow[t]{2}{*}{ Meat } & $0.188^{\star \star \star}$ & $0.229^{\star \star \star}$ & $0.219^{\star \star \star}$ & $0.185^{\star \star \star}$ & $0.218^{\star \star \star}$ \\
\hline & $(0.04)$ & $(0.03)$ & $(0.04)$ & $(0.04)$ & $(0.04)$ \\
\hline \multirow[t]{2}{*}{ School Supplies } & -0.026 & -0.031 & -0.029 & -0.047 & -0.026 \\
\hline & $(0.04)$ & $(0.03)$ & $(0.03)$ & $(0.03)$ & $(0.04)$ \\
\hline \multirow[t]{2}{*}{ Airtime } & $-0.072^{* *}$ & -0.040 & -0.041 & $-0.051^{*}$ & -0.036 \\
\hline & $(0.03)$ & $(0.03)$ & $(0.03)$ & $(0.03)$ & $(0.03)$ \\
\hline \multirow[t]{2}{*}{ Question: Small Quantities } & & $0.156^{* * *}$ & $0.156^{\star * *}$ & $0.156^{* * *}$ & $0.156^{\star * *}$ \\
\hline & & $(0.01)$ & $(0.01)$ & $(0.01)$ & $(0.01)$ \\
\hline Factor: Storage & & & $0.097^{*}$ & 0.066 & \\
\hline Storage*Matooke & & & & & 0.074 \\
\hline Storage*Sugar & & & & & -0.102 \\
\hline Storage*Beef & & & & & $0.133^{*}$ \\
\hline Factor: Resale & & & -0.050 & -0.009 & \\
\hline Resale*Matooke & & & & & -0.038 \\
\hline Resale*Sugar & & & & & 0.001 \\
\hline Resale*Beef & & & & & -0.043 \\
\hline Resale*School & & & & & -0.149 \\
\hline Factor: Future Price & & & -0.022 & -0.004 & \\
\hline Price*Matooke & & & & & 0.023 \\
\hline Price*Sugar & & & & & -0.027 \\
\hline Price*Beef & & & & & -0.104 \\
\hline Price ${ }^{\star}$ School & & & & & -0.002 \\
\hline Factor: Uncertainty about payment & & & $0.148^{*}$ & $0.163^{*}$ & \\
\hline UncertMatooke & & & & & $0.353^{* *}$ \\
\hline Uncert*Sugar & & & & & $0.262^{*}$ \\
\hline Uncert*Beef & & & & & 0.202 \\
\hline UncertSchool & & & & & 0.054 \\
\hline Uncert*Airtime & & & & & -0.099 \\
\hline Factor: Desire for good today & & & & $0.232^{\star \star *}$ & \\
\hline Factor: Desire for good in a month & & & & $-0.159^{* \star \star}$ & \\
\hline Constant & 0.88 & 0.71 & 0.70 & 0.70 & 0.71 \\
\hline Individual Fixed Effects & & & Yes & Yes & Yes \\
\hline Households & 449 & 449 & 449 & 449 & 449 \\
\hline Observations & 2,694 & 5,388 & 5,388 & 5,388 & 5,388 \\
\hline $\begin{array}{l}\text { Notes: }{ }^{* * *},{ }^{* *},{ }^{*} \text { : significant at } 1,5 \mathrm{a} \\
\text { results from the regression of the di } \\
\text { captures the average discount rate } \\
\text { errors clustered at the individual lev }\end{array}$ & $\begin{array}{l}\text { and } 10 \% \text { level, resp } \\
\text { iscount rates on gc } \\
\text { for money. Colum } \\
\text { el in parenthesis, }\end{array}$ & $\begin{array}{l}\text { tively. Mon } \\
\text { s and ques } \\
\text { restricts th } \\
\text { ilable upon }\end{array}$ & $\begin{array}{l}\text { he omitte } \\
\text { nagnitude } \\
\text { a to small- } \\
\text { est where }\end{array}$ & $\begin{array}{l}\text { d. Columns } \\
\text { imies, the } \\
\text { tities choice } \\
\text { ed. }\end{array}$ & $\begin{array}{l}\text { show the } \\
\text { tant }\end{array}$ \\
\hline
\end{tabular}


Table 7. Joint Estimation and Rel Rewards

\begin{tabular}{|c|c|c|c|c|c|c|c|c|c|c|c|}
\hline $\begin{array}{l}\text { Individual } \\
\text { Estimation for } \\
\text { each good }\end{array}$ & $\begin{array}{c}\text { Coefficient } \\
\text { (1) }\end{array}$ & $\begin{array}{c}95 \% \\
\text { Lower } \\
\text { Bound } \\
(2)\end{array}$ & $\begin{array}{c}95 \% \\
\text { Upper } \\
\text { Bound } \\
(3)\end{array}$ & $\begin{array}{l}\text { Predicted } \\
\text { Value for } \\
\text { Females+ } \\
\text { (4) }\end{array}$ & $\begin{array}{c}\text { Average } \\
\text { Predicted } \\
\text { Value with } \\
\text { controls+++ } \\
\text { (5) }\end{array}$ & $\begin{array}{c}\text { Storage } \\
(6)\end{array}$ & $\begin{array}{c}\text { Resale } \\
(7)\end{array}$ & $\begin{array}{c}\text { Future } \\
\text { Price } \\
(8)\end{array}$ & $\begin{array}{l}\text { ermining Cho } \\
\text { Uncertainty } \\
\text { about } \\
\text { payment } \\
\text { (9) }\end{array}$ & $\begin{array}{l}\text { Desice } \\
\text { have } \\
\text { Today } \\
(10)\end{array}$ & $\begin{array}{c}\text { Desire to } \\
\text { have in a } \\
\text { month } \\
(11)\end{array}$ \\
\hline Sugar & 0.616 & 0.53 & 0.71 & 0.55 & 0.70 & (0) & (0) & (0) & $* * * *(+)$ & $* * * *(+)$ & $* * \star *(-)$ \\
\hline Beef & 0.591 & 0.50 & 0.68 & 0.52 & 0.66 & (o) & (o) & (o) & $* * \star(+)$ & $* * *(+)$ & $* * *(-)$ \\
\hline Matooke & 0.537 & 0.45 & 0.62 & 0.49 & 0.60 & (o) & * $(-)$ & (o) & $* * *(+)$ & $* * *(+)$ & ${ }^{* * *}(-)$ \\
\hline Money & 0.417 & 0.35 & 0.48 & 0.36 & 0.49 & (o) & (o) & (o) & (o) & $* * *(+)$ & $* * *(-)$ \\
\hline School Supplies & 0.393 & 0.33 & 0.45 & 0.35 & 0.45 & (o) & (o) & (o) & (o) & $* * *(+)$ & ${ }^{* * *}(-)$ \\
\hline Airtime & 0.392 & 0.33 & 0.45 & 0.33 & 0.45 & (o) & (o) & (0) & $* * *(+)$ & $* * *(+)$ & ${ }^{* * *}(-)$ \\
\hline Observations & 11,220 & & & & & & & & & & \\
\hline Households & 449 & & & & & & & & & & \\
\hline
\end{tabular}

Notes: Column 1-3 present MLE estimates for each good, the upper and lower bounds were calculated on the basis of standard errors clustered at the individual level. The risk aversion parameter and structural errors terms for risk and time preferences were also re-estimated in each case. +Column 4 presents the predicted discount rate for females based on the coefficient obtained when we allow both the discount rate and risk aversion parameter to depend on observable characteristics, dummies for being female, married, low ability scores and literate were also included, we included as well a small-quantities dummy. ++ Column 5 presents predicted discounted rates including also the factors in columns 6-11 in the regression. (+) and (-) means positive or negative coefficient on the regression, (0) means non-significant effect. ${ }^{* * *}$, ${ }^{* *}$, mean significant at 1,5 and $10 \%$ level, respectively. 
Table 8. Joint Estimation and Real Rewards. Effect of Background Consumption

\begin{tabular}{|c|c|c|c|c|c|c|}
\hline $\begin{array}{c}\text { Individual } \\
\text { Estimation for each } \\
\text { good }\end{array}$ & $\begin{array}{c}\text { Sugar } \\
\text { (1) }\end{array}$ & $\begin{array}{l}\text { Beef } \\
(2)\end{array}$ & $\begin{array}{c}\text { Matooke } \\
\text { (3) }\end{array}$ & $\begin{array}{c}\text { Money } \\
\text { (4) }\end{array}$ & $\begin{array}{c}\text { School } \\
\text { Supplies } \\
(5)\end{array}$ & $\begin{array}{c}\text { Airtime } \\
\text { (6) }\end{array}$ \\
\hline \multicolumn{7}{|l|}{ Background 1+ } \\
\hline Coefficient & 0.605 & 0.596 & 0.537 & & 0.377 & 0.390 \\
\hline 95\% Lower Bound & 0.51 & 0.51 & 0.45 & & 0.31 & 0.33 \\
\hline 95\% Upper Bound & 0.70 & 0.69 & 0.63 & & 0.44 & 0.45 \\
\hline \multicolumn{7}{|l|}{ Background 2++ } \\
\hline Coefficient & 0.765 & 0.613 & 0.511 & & 0.346 & 0.364 \\
\hline 95\% Lower Bound & 0.40 & 0.42 & 0.35 & & 0.18 & 0.28 \\
\hline 95\% Upper Bound & 1.13 & 0.81 & 0.67 & & 0.51 & 0.45 \\
\hline \multicolumn{7}{|l|}{ Background 3+++ } \\
\hline Coefficient & 0.668 & 0.593 & 0.550 & & & \\
\hline 95\% Lower Bound & 0.56 & 0.50 & 0.46 & & & \\
\hline 95\% Upper Bound & 0.78 & 0.69 & 0.64 & & & \\
\hline \multicolumn{7}{|l|}{ Background 4++++ } \\
\hline Coefficient & 0.725 & 0.710 & 0.615 & 0.446 & 0.431 & 0.455 \\
\hline 95\% Lower Bound & 0.62 & 0.60 & 0.52 & 0.37 & 0.36 & 0.38 \\
\hline 95\% Upper Bound & 0.83 & 0.82 & 0.71 & 0.52 & 0.50 & 0.53 \\
\hline
\end{tabular}

Notes: MLE estimates for each good, upper and lower bounds calculated on the basis of standard errors clustered at the individual level. Estimation includes: + quantity of the good available at home at the moment of survey, ++ also expected quantity available at home in a month, +++ daily typical consumption and reported days to consume reward, ++++ daily typical consumption and estimated days to consume reward. 
Table 9. Elasticities and Budget Shares

\begin{tabular}{lccccc}
\hline \hline \multicolumn{1}{c}{ Good } & Coefficient & $\begin{array}{c}\text { Standard } \\
\text { Error }\end{array}$ & $\begin{array}{c}\text { Mean } \\
\text { Share }\end{array}$ & $\begin{array}{c}\text { Mean } \\
\text { Share if } \\
>\mathbf{0}\end{array}$ & $\begin{array}{c}\text { N with } \\
\text { positive } \\
\text { consumption }\end{array}$ \\
\hline High Discount Goods* $^{*}$ & $\mathbf{0 . 9 1}$ & $\mathbf{0 . 0 0 6}$ & $\mathbf{0 . 4 7}$ & & 2,060 \\
Low Discount Goods $^{* *}$ & $\mathbf{1 . 0 6}$ & $\mathbf{0 . 0 0 5}$ & $\mathbf{0 . 5 3}$ & & 2,189 \\
School Supplies & $\mathbf{1 . 0 3}$ & $\mathbf{0 . 0 0 1}$ & $\mathbf{0 . 1 8}$ & 0.26 & 1,552 \\
Sugar & $\mathbf{0 . 6 8}$ & $\mathbf{0 . 0 0 9}$ & $\mathbf{0 . 1 7}$ & 0.19 & 1,955 \\
Matooke & $\mathbf{1 . 0 8}$ & $\mathbf{0 . 0 0 3}$ & $\mathbf{0 . 1 7}$ & 0.30 & 1,214 \\
Meat & $\mathbf{0 . 8 7}$ & $\mathbf{0 . 0 0 7}$ & $\mathbf{0 . 1 3}$ & 0.19 & 1,456 \\
Clothes & 1.12 & 0.004 & 0.07 & 0.29 & 501 \\
Beans & 1.03 & 0.002 & 0.06 & 0.14 & 1,005 \\
Airtime & 1.07 & 0.006 & 0.06 & 0.09 & 1,365 \\
Salt & 0.34 & 0.053 & 0.03 & 0.04 & 2,102 \\
Snacks & 0.94 & 0.003 & 0.03 & 0.06 & 1,262 \\
Saloon & 0.83 & 0.008 & 0.02 & 0.09 & 1,300 \\
Lotion & 0.93 & 0.005 & 0.02 & 0.08 & 451 \\
Meals Out & 1.12 & 0.012 & 0.02 & 0.12 & 310 \\
Entertainment & 1.06 & 0.006 & 0.01 & 0.05 & 153 \\
Soda & 1.14 & 0.005 & 0.01 & 0.04 & 624 \\
Perfume & 1.04 & 0.006 & 0.00 & 0.08 & 92 \\
\hline
\end{tabular}

Notes: * Sugar, meat and matooke. ** All the other goods in the list (including also expenditures on beer and bar games). 
Figure 1. Nonparametric Engel Curves

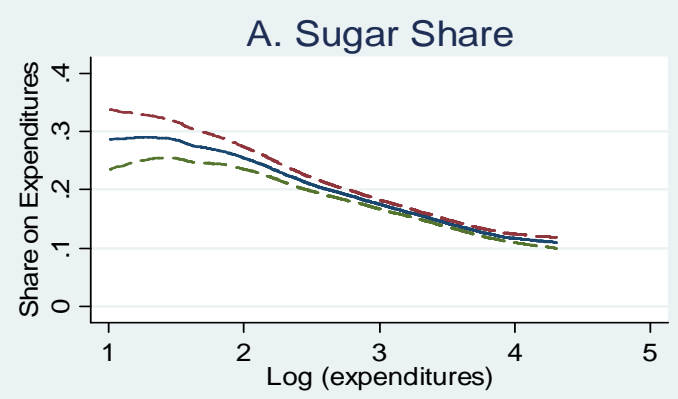

B. Meat Share
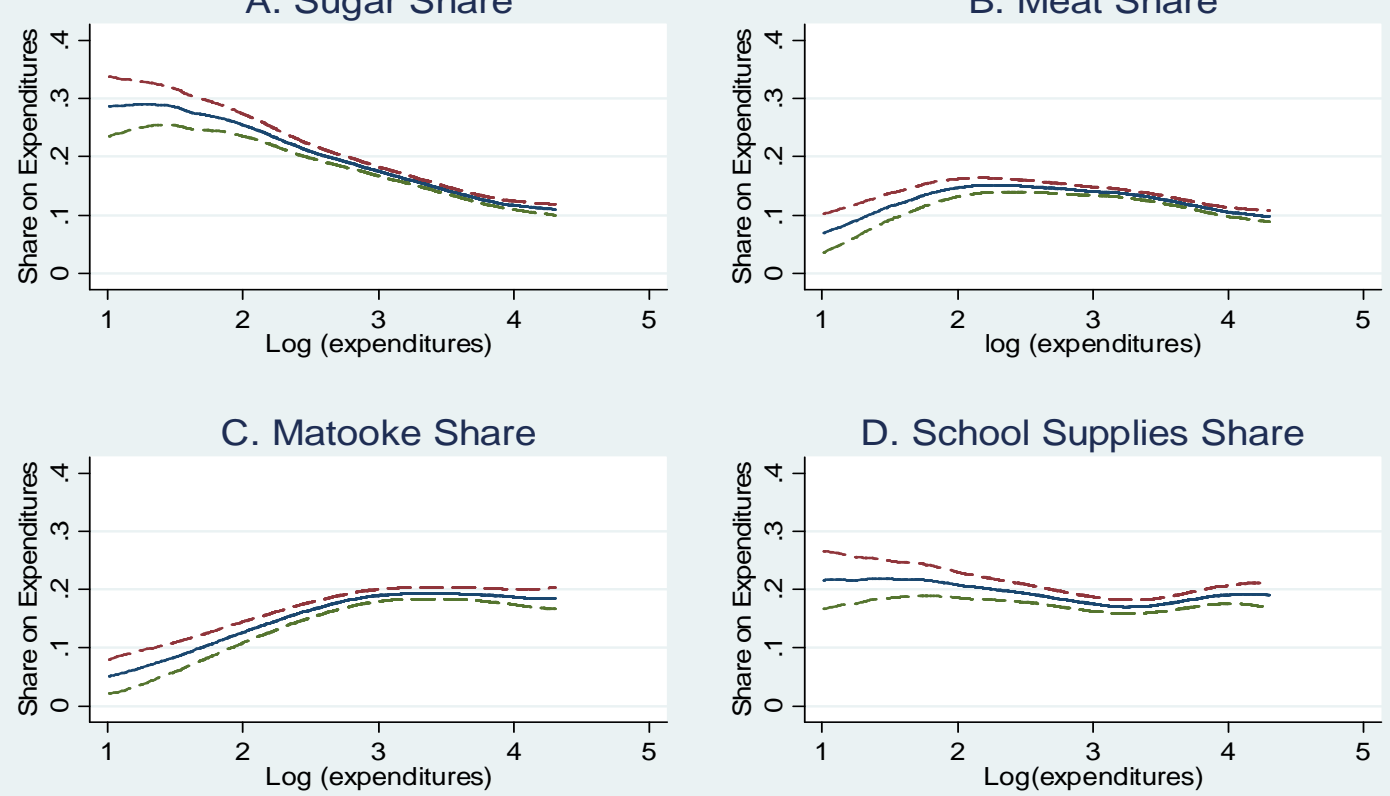
Figure 2. Engel Curves, High and Low Discount Goods

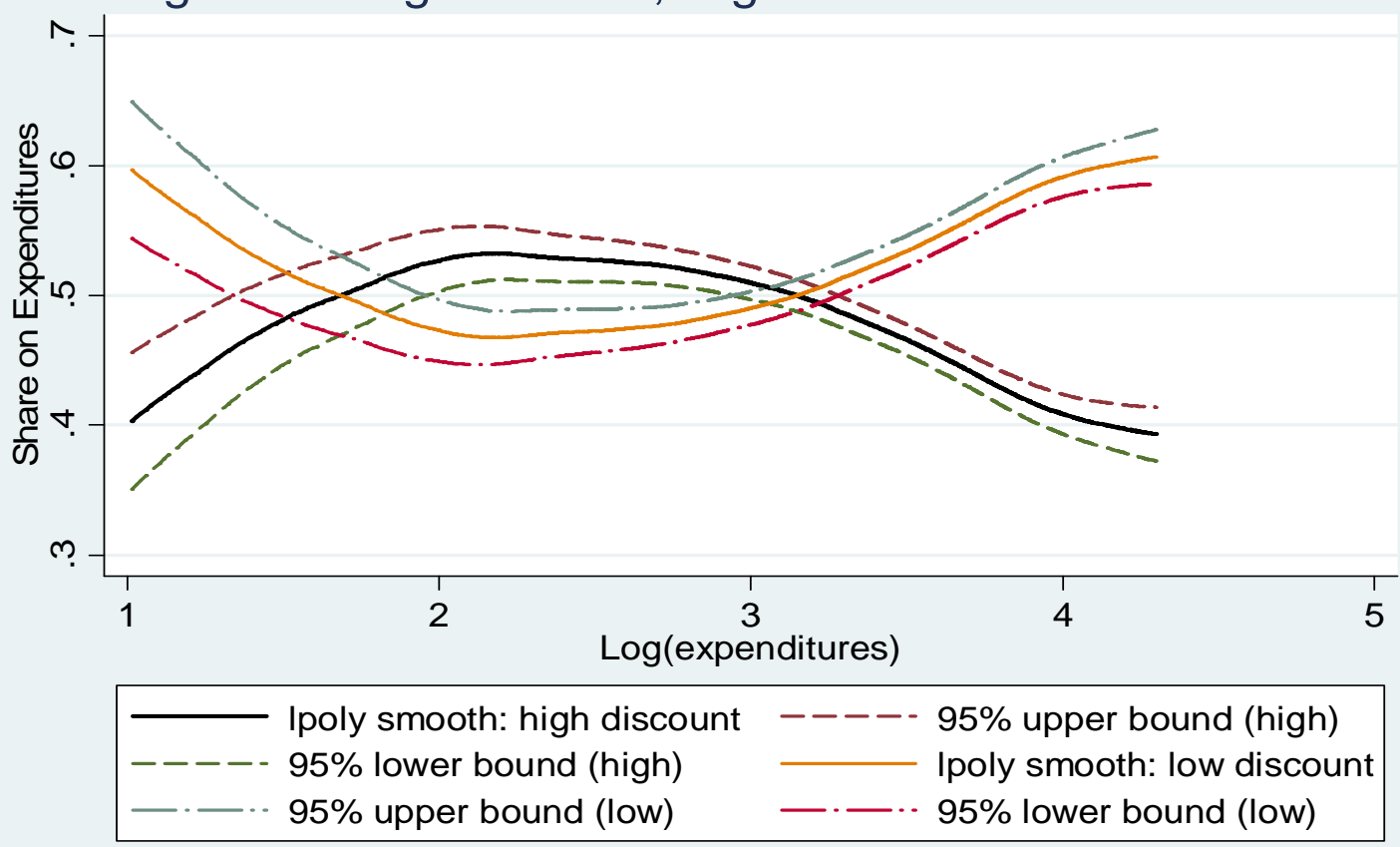

